\title{
Density functional theory study of mercury adsorption on metal surfaces
}

\author{
Janice A. Steckel* \\ National Energy Technology Laboratory, United States Department of Energy, P.O. Box 10940, Pittsburgh, Pennsylvania 15236, USA \\ and Parsons Project Services, Inc., South Park, Pennsylvania 15129, USA
}

(Received 21 September 2007; published 10 March 2008)

\begin{abstract}
Density functional theory (DFT) calculations are used to characterize the interaction of mercury with copper, nickel, palladium, platinum, silver, and gold surfaces. Mercury binds relatively strongly to all the metal surfaces studied, with binding energies up to $\sim 1 \mathrm{eV}$ for Pt and Pd. DFT calculations underestimate the energy of adsorption with respect to available experimental data. Plane-wave DFT results using the local density approximation and the Perdew-Wang 1991 and Perdew-Burke-Ernzerhof parametrizations of the generalized gradient approximation indicate that binding of mercury at hollow sites is preferred over binding at top or bridge sites. The interaction with mercury in order of increasing reactivity over the six metals studied is $\mathrm{Ag}$ $<\mathrm{Au}<\mathrm{Cu}<\mathrm{Ni}<\mathrm{Pt}<\mathrm{Pd}$. Binding is stronger on the (001) faces of the metal surfaces, where mercury is situated in fourfold hollow sites as opposed to the threefold hollow sites on (111) faces. In general, mercury adsorption leads to decreases in the work function; adsorbate-induced work function changes are particularly dramatic on Pt.
\end{abstract}

DOI: 10.1103/PhysRevB.77.115412

PACS number(s): 68.43.Bc, 71.15.Nc, 73.20.At, 73.20.Hb

\section{INTRODUCTION}

Many natural materials such as coal and oil contain small amounts of mercury. When these materials are used on a large scale, such as in the burning of fuel to produce electricity, mercury is released into the atmosphere. Current releases of mercury into the atmosphere as a result of human activity are estimated to be $\sim 2400$ tons per year. ${ }^{1}$ Mercury contamination of the atmosphere and the bioaccumulation of mercury in fish have led to policy changes in the United States including a two-phase cap on mercury emissions from coal-fired power plants. Emission reductions for the first phase are expected to be achieved as a cobenefit of technologies that control other air pollutants, but it is expected that the second, lower cap on emissions will require the development of dedicated mercury-control technologies. ${ }^{2}$

About $25 \%$ of the electricity produced from coal in the United States comes from plants that are equipped with wet flue gas desulfurization (WFGD) units for the removal of sulfur (responsible for acid rain). The WFGD units are capable of removing $\sim 90 \%$ of oxidized mercury from the flue, but they do not remove mercury in elemental form, and therefore the overall efficiency of mercury removal across a WFGD unit will vary according to the speciation of the mercury that enters the device. ${ }^{3}$ In order to ensure the efficiency of mercury removal via WFGD units, there is a need for effective and regenerable mercury oxidation catalyst materials, and noble metals such as copper, silver, gold, and palladium are being investigated for this application. ${ }^{4-6}$

Noble metals including platinum, gold, palladium, and copper have been investigated for incorporation in novel mercury removal sorbents, both for conventional coal-fired power plants and in the context (i.e., different temperature and pressure) of new integrated gasification combined-cycle (IGCC) power generation plants. ${ }^{7,8}$

Despite the interest in using metals in mercury removal, very little research has been carried out to determine basic information about the binding of mercury to metal surfaces.
In this paper, density functional theory (DFT) calculations are used to characterize the bonding of mercury to the surface of a series of metals. This project represents a survey of the adsorption interaction of mercury with the ideal metal surfaces as calculated by plane-wave DFT methods. In addition to providing fundamental information about the interaction of mercury with specific metal surfaces, comparisons are made between metals and between different overlayer patterns.

\section{PREVIOUS WORK}

Theoretical calculations on mercury can be quite challenging as bonding in mercury varies from primarily van der Waals in the dimer to covalent in small clusters to metallic in large clusters and in the bulk. ${ }^{9,10}$ Relativistic effects play an important role in the degree of $6 s-6 p$ and $6 s-5 d$ hybridization in the electronic structure and the magnitude of metallic bonding in mercury. ${ }^{11,12}$ All-electron calculations on mercury are computationally expensive, and much effort has been devoted to the development of effective core potentials (ECPs) as well as balanced basis sets for use in mercury calculations. ${ }^{13-18}$ A sophisticated description of electron correlation and treatment of relativistic effects including spinorbit coupling are desirable for highly accurate results. ${ }^{19-21}$ The use of ECPs generated from relativistic all-electron calculations can not only reduce the number of electrons that must be treated explicitly, but contributions of the most important relativistic operators are transferred to the pseudopotential. ${ }^{14}$ Much high-quality ab initio work on small mercury compounds (including the mercury halides) has been performed using wave-function-based methods and small-core ECPs. ${ }^{22-25}$ For small molecules, these methods are state of the art, but there is also a push to find ways to perform simulations on larger mercury clusters as well as mercury adsorption to the surfaces of solids. ${ }^{9,10,21,26}$ Calculations carried out by Gaston et al. on mercury dimers, mercury clusters, and bulk mercury have revealed inaccuracies 
in many of the common theoretical tools in use for larger clusters or solids. ${ }^{9,20,21}$ Despite its shortcomings, DFT remains an important tool for the description of mercury and compounds or materials interacting with mercury, quite simply because more accurate methods cannot currently be applied to very large clusters or with the use of periodic boundary conditions. The use of a relativistic formulation of DFT in mercury bonding is desirable but it is difficult to treat models larger than $\sim 30$ heavy atoms. Using four-component relativistic DFT with a series of embedded-cluster models of various sizes, Sarpe-Tudoran and co-workers calculated binding energies for $\mathrm{Hg}$ to $\mathrm{Au}(001)$ of $-1.01,-1.52$, and $-0.84 \mathrm{eV}$ for top, bridge, and hollow sites, respectively. ${ }^{27}$ The authors point out that the binding energies were not converged with respect to cluster size due to the high cost of the theoretical method.

There have been a number of experimental studies of mercury on metal surfaces. ${ }^{28-35}$ On the (001) surface of Ag, where the mesh dimension is close to the $\mathrm{Hg}-\mathrm{Hg}$ distance in $\alpha$ - Hg $(3.005 \AA),{ }^{21}$ initial growth of $\mathrm{Hg}$ layers has been shown to be pseudomorphic and a $c(1 \times 1)$ low-energy electron diffraction (LEED) pattern has been observed. ${ }^{29,32,34}$ The heat of desorption for the $c(1 \times 1)$ phase of $\mathrm{Hg}$ on $\mathrm{Ag}(001)$ was reported to be $0.63 \mathrm{eV} .{ }^{32}$ The lattice dimensions of $\mathrm{Cu}$ and $\mathrm{Ni}$ are smaller, and the $c(1 \times 1)$ phase has not been observed. The heats of desorption for the $c(2 \times 2)$ and $c(4 \times 4)$ phases of $\mathrm{Hg}$ on $\mathrm{Cu}(001)$ was reported to be 0.74 and $0.70 \mathrm{eV}$, respectively. ${ }^{32}$

Several experimental studies were carried out on mercury adsorption on $\mathrm{Ni}(001)$ and $\mathrm{Ni}(111)$ surfaces by Jones and collaborators. $28,30,31,33$ Jones and Tong proposed a mobile two-dimensional lattice gas model for mercury adsorption on $\mathrm{Ni}(001)$ at low coverages, followed by a transition to an immobile $c(2 \times 2)$ adsorption as coverage increases and to an incommensurate overlayer at higher coverages. They found strong chemisorption of mercury on $\mathrm{Ni}(001)$, with an associated $c(2 \times 2)$ LEED pattern (except for the highest coverages, for which the LEED pattern was more complicated). They measured a heat of adsorption at zero coverage of $1.19 \pm 0.16 \mathrm{eV}$; as coverage increased, so did the heat of adsorption, peaking at $1.71 \pm 0.16 \mathrm{eV}$ and then dropping to $1.04 \pm 0.16 \mathrm{eV}$.

Using standing $\mathrm{x}$-ray wave-field absorption experiments, Prince et al. studied the $c(2 \times 2)-\mathrm{Hg} / \mathrm{Ni}(001)$ overlayer. ${ }^{30}$ They measured a $\mathrm{Hg}$ to $\mathrm{Ni}$ lattice plane spacing of $0.6 \pm 0.1 \AA$, which is consistent with with $\mathrm{Hg}$ adsorption at bridge sites. Subsequently, Poulsen et al. performed transmission channeling studies and concluded that adsorption of $\mathrm{Hg}$ on $\mathrm{Ni}(001)$ below 0.5 monolayer (ML) occurs at the fourfold hollow sites at a height of $2.25 \pm 0.10 \AA .{ }^{34}$ On the $\mathrm{Ni}(111)$ surface, Singh and Jones measured a heat of adsorption of $1.14 \pm 0.41 \mathrm{eV}$ at zero coverage, $2.07 \pm 0.41 \mathrm{eV}$ for the $(\sqrt{3} \times \sqrt{3}) R 30^{\circ}-\mathrm{Hg} / \mathrm{Ni}(111) \quad 0.333 \mathrm{ML}$ overlayer and $0.83 \pm 0.41 \mathrm{eV}$ for the $p(2 \times 2)-\mathrm{Hg} / \mathrm{Ni}(111) \quad 0.5 \mathrm{ML}$ overlayer. ${ }^{31}$ The increase of the heat of adsorption of mercury on the $\mathrm{Ni}(111)$ surface as a function of increasing coverage is similar to that which was found on the $\mathrm{Ni}(001)$ surface. Mercury overlayers have also attracted the interest of various scientists in the context of the nonmetal to metal transition occurring in mercury overlayers and thin films. ${ }^{36,37}$

Recently, Soverna and colleagues used thermochromatic methods to evaluate the adsorption enthalpies of mercury on noble metal surfaces. ${ }^{35}$ They found that mercury interacted with the following metals with increasing strength: $\mathrm{Ag}<\mathrm{Ni}$ $<\mathrm{Au}<\mathrm{Pd}<\mathrm{Pt}$. The binding energies obtained were $\mathrm{Ag}$, $-0.91 \pm 0.03 \mathrm{eV} ; \mathrm{Ni},-0.92 \pm 0.03 \mathrm{eV} ; \mathrm{Au},-1.01 \pm 0.03 \mathrm{eV}$; $\mathrm{Pd},-1.44 \pm 0.04 \mathrm{eV}$; and $\mathrm{Pt},-1.49 \pm 0.05 \mathrm{eV}$.

\section{METHODS}

As discussed above, there are shortcomings that accompany the use of DFT for the calculation of mercury adsorption on metals, but plane-wave DFT remains the practical compromise between accuracy and computational demand for studies of adsorption on metal surfaces in which periodic boundary conditions or a very large model are absolutely necessary. The DFT calculations were performed with the Vienna ab initio simulation package (VASP), ${ }^{38,39}$ and made use of the projector augmented wave (PAW) method of Blöchl. ${ }^{40,41}$ The Perdew-Zunger parametrization of the local exchange-correlation functional according to the quantum Monte Carlo simulations of Ceperley and Alder was used [hereafter denoted as the local density approximation (LDA)]. ${ }^{42,43}$ Two versions of nonlocal corrections in the form of the generalized gradient approximation were also used; that of Perdew and Wang ${ }^{44,45}$ is denoted PW91 and that of Perdew, Burke, and Ernzerhof ${ }^{46}$ is denoted PBE.

To accelerate the convergence, a generalized Gaussian smearing according to Methfessel and Paxton was adopted with order 1 and a width of $0.05 \mathrm{eV} .{ }^{47}$ The size of the smearing width was chosen in order to keep the difference between the calculated free energy and total energy smaller than $1 \mathrm{meV} /$ atom. All total energies have been extrapolated to $k_{B} T=0 \mathrm{eV}$.

\section{A. Methods: Bulk properties}

Calculations were carried out on bulk models of $\mathrm{Ag}, \mathrm{Au}$, $\mathrm{Cu}, \mathrm{Ni}, \mathrm{Pd}$, and $\mathrm{Pt}$ in order to compare calculated bulk properties with experimentally measured properties for the density functionals mentioned above (LDA, PW91, and PBE). The volume versus energy data were fit to a BirchMurnaghan equation of state to calculate the equilibrium lattice constant, bulk modulus, and cohesive energy. The details are presented as supplementary information (see Ref. 48).

As in previous reports, ${ }^{49}$ DFT methods predict lattice constants in very good agreement with experimentally measured values. The functional that provided the best overall results for the six metals was the PBE functional, and therefore the PBE functional was used in most of the subsequent calculations.

\section{B. Methods: Slab models}

Interactions of mercury with the (001) and (111) surfaces of $\mathrm{Ag}, \mathrm{Au}, \mathrm{Cu}, \mathrm{Ni}, \mathrm{Pd}$, and $\mathrm{Pt}$ have been studied with planewave DFT calculations on slab models. The metal surfaces have been represented with asymmetric four-layer slab models with atoms in the two lower layers fixed at ideal bulk 
positions. Atoms in the top two layers of the slab, as well as the $\mathrm{Hg}$ overlayer, were allowed to relax. Slabs were separated by vacuum layers of $\sim 10 \AA$ or more. Atomic relaxations were carried out by minimization of the HellmannFeynman forces via a conjugate gradients algorithm. Relaxations were stopped when the absolute values of calculated forces on unfixed atoms were less than 1.0 $\times 10^{-5} \mathrm{eV} / \AA$.

Optimization of the geometry for each supercell was followed by a separate single-point energy calculation at the converged geometry with fast Fourier transform (FFT) meshes sufficiently large to include all wave vectors up to $2 G_{\text {cut }}$ where $E_{\text {cut }}=\frac{\hbar^{2}}{2 m_{e}} G_{\text {cut }}^{2}$. The Kohn-Sham ground states were calculated via either a Davidson block iteration scheme $^{50}$ or a combination of the Davidson scheme with a residual minimization method, direct inversion in the iterative subspace (RMM-DIIS) scheme. ${ }^{51,52}$ The break point for the electronic self-consistency loop in the higher-accuracy single-point calculations was an energy difference of less than $1.0 \times 10^{-7} \mathrm{eV}$.

For the slab calculations, the dipole was calculated in the surface normal direction and a compensating linear electrostatic potential was added to the local potential in the void region of the supercell in order to correct for the errors introduced by the use of periodic boundary conditions with asymmetric slab models. ${ }^{53} \mathrm{~A}$ Bader charge analysis was carried out on the overlayers to estimate the charge transfer to or from the adsorbed mercury atoms. ${ }^{54}$

In order to calculate the work function, the plane-average electrostatic potential along the surface normal was computed; the work function $\Phi$ was computed for clean and mercury-covered surfaces as $\Phi=V_{0}-E_{F}$ where $E_{F}$ is the Fermi energy and $V_{0}$ is the value of the electrostatic potential in the void region of the supercell, which mimics the vacuum. ${ }^{55,56}$ The computed values of $\Phi$ for the clean, relaxed surfaces are included in the supplementary information. ${ }^{48}$

The $k$ points were chosen according to the Monkhorst Pack scheme. ${ }^{57}$ Convergence with $k$-point sampling was investigated for the $(1 \times 1)-\mathrm{Hg} / \mathrm{Pd}(100)$ overlayer; results are presented in the supplementary information. ${ }^{48}$ The energy of adsorption is converged to within $\pm 0.02 \mathrm{eV}$ even with the $6 \times 6 \times 1$ grid. For subsequent calculations on the (1 $\times 1)-\mathrm{Hg} / \mathrm{M}(100)$ supercell, an $8 \times 8 \times 1$ Monkhorst-Pack grid was employed. A $6 \times 6 \times 1$ Monkhorst-Pack grid has been used for integration in reciprocal space for all other supercells except for the relatively large $(2 \sqrt{3}$ $\times 3)-\mathrm{Hg} / \mathrm{M}(111)$ overlayer, for which a $4 \times 6 \times 1$ grid was chosen. Based on the data presented in the supplementary information, ${ }^{48}$ the calculated work function for the production calculations may be considered converged only to within approximately $\pm 0.05 \mathrm{eV}$ for the bare metal surfaces and $\pm 0.15 \mathrm{eV}$ for the mercury overlayers.

Convergence as a function of the size of the plane-wave basis set was investigated using the $(1 \times 1)-\mathrm{Hg} / \mathrm{Pd}(001)$ model. The results, presented in the supplementary information, ${ }^{48}$ confirm that both the energy of adsorption and the work function are converged to within $\pm 0.01 \mathrm{eV}$ with respect to the basis set for $E_{c u t}=330 \mathrm{eV}$. For all subsequent calculations, a basis set consisting of plane waves with energy up to $E_{\text {cut }}=380 \mathrm{eV}$ was used.
TABLE I. Binding enegies (in eV) for high-symmetry sites on the $c(4 \times 4)-\mathrm{Hg} / \mathrm{Au}(001) 0.125 \mathrm{ML}$ overlayer calculated using the PBE, PW91, and LDA functionals. Results of cluster relativistic DFT calculations of Sarpe-Tudoran et al. (Ref. 27) are presented for comparison.

\begin{tabular}{lcccc}
\hline \hline Site & $E_{a d s}(\mathrm{PBE})$ & $E_{a d s}(\mathrm{PW} 91)$ & $E_{a d s}(\mathrm{LDA})$ & $E_{a d s}($ Ref. 27) \\
\hline Hollow & -0.61 & -0.66 & -1.48 & -0.84 \\
Bridge & -0.47 & -0.50 & -1.11 & -1.52 \\
Top & -0.36 & -0.39 & -0.84 & -1.02 \\
\hline \hline
\end{tabular}

Calculations on the bare and Hg-covered (1 $\times 1)-\mathrm{Hg} / \mathrm{Pd}(001)$ overlayers were carried out with various numbers of layers in the metal slab in order to examine convergence with respect to the number of layers in the slab. Results are presented in the supplementary information. ${ }^{48}$ The binding energy, work function for the bare metal, and change in work function upon $\mathrm{Hg}$ adsorption are converged to within a factor of $\pm 0.03, \pm 0.05$, and $\pm 0.08 \mathrm{eV}$, respectively, with a four-layer slab. Since the cost of the calculations scales steeply with system size, four-layer slabs were used for subsequent calculations.

\section{RESULTS: MERCURY ON METAL SURFACES}

Hollow, top, and bridge sites were investigated for all the overlayers included in this study. Representative results are presented (in Table I) for low coverage on the the $\mathrm{Au}(001)$ surface using three functionals (LDA, PW91, and PBE). The PW91 and PBE functionals yield very similar results while the LDA, as is common, shows significant overbinding. Binding at the hollow sites was preferred, followed by the bridge site, with the top site being the least favored, for all overlayers included in this study. The differences in adsorption energies for mercury at the fcc and hep hollow sites on the (111) surfaces were negligible. All data presented hereafter are for adsorption at hollow sites and were generated using the PBE functional.

Mercury is predicted to bind to $\mathrm{Ag}, \mathrm{Au}, \mathrm{Cu}, \mathrm{Ni}, \mathrm{Pd}$, and $\mathrm{Pt}$ with binding energies between -0.30 and $-1.10 \mathrm{eV}$. Binding energies of this order of magnitude are sizable and denote chemical interactions between the metal surfaces and adsorbed mercury. Of the six metals studied here, DFT predicts that $\mathrm{Pd}$ and $\mathrm{Pt}$ bind $\mathrm{Hg}$ atoms the most strongly $\left(E_{a d s}=\right.$ -0.58 to $-1.10 \mathrm{eV})$, followed by $\mathrm{Ni}$ and $\mathrm{Cu}\left(E_{a d s}=\right.$ -0.48 to $-0.82 \mathrm{eV})$. $\mathrm{Ag}$ and $\mathrm{Au}$ bind $\mathrm{Hg}$ the most weakly $\left(E_{a d s}=-0.30\right.$ to $\left.-0.51 \mathrm{eV}\right)$.

For all metal surfaces studied in this work except $\operatorname{Ag}(001)$, the adsorption of mercury is predicted to cause a negative change in the work function. The change in work function is calculated to be positive or minimally negative for $\operatorname{Ag}(001)$ surfaces, significantly negative $(\Delta \Phi \approx$ -0.25 to $-0.85 \mathrm{eV}$ ) for $\mathrm{Ag}(111), \mathrm{Au}, \mathrm{Cu}$, and $\mathrm{Ni}$, and sizably negative $(\Delta \Phi \approx-0.1$ to $-1.5 \mathrm{eV})$ for higher coverages on $\mathrm{Pd}$ and, especially, Pt. The binding energies for mercury on palladium and to platinum are very similar, but the change in work function is calculated to be almost twice as large on 
TABLE II. Hg adsorption on (111) metal surfaces on hollow sites: $\theta$ denotes coverage, $E_{a d s}$ denotes binding energy, $M-\mathrm{Hg}$ and $\mathrm{Hg}-\mathrm{Hg}$ denote distances between adsorbed $\mathrm{Hg}$ and substrate or neighboring $\mathrm{Hg}$ atoms, respectively, $\Phi$ is the calculated work function of the bare metal, and $\Delta \Phi$ and $\Delta Q$ are the adsorptioninduced changes in work function and charge on $\mathrm{Hg}$.

\begin{tabular}{|c|c|c|c|c|c|c|c|}
\hline Overlayer & $\begin{array}{c}\theta \\
(\mathrm{ML})\end{array}$ & $\begin{array}{l}E_{a d s} \\
(\mathrm{eV})\end{array}$ & $\begin{array}{c}M-\mathrm{Hg} \\
(\AA)\end{array}$ & $\begin{array}{c}\mathrm{Hg}-\mathrm{Hg} \\
(\AA)\end{array}$ & $\begin{array}{c}\Phi \\
(\mathrm{eV})\end{array}$ & $\begin{array}{c}\Delta \Phi \\
(\mathrm{eV})\end{array}$ & $\begin{array}{c}\Delta Q \\
\text { (a.u.) }\end{array}$ \\
\hline$(2 \sqrt{3} \times 3)-\mathrm{Hg} / \mathrm{Ag}(111)$ & 0.083 & -0.34 & 3.00 & 8.83 & 4.48 & -0.24 & -0.03 \\
\hline$(2 \sqrt{3} \times 3)-\mathrm{Hg} / \mathrm{Au}(111)$ & 0.083 & -0.36 & 2.99 & 8.85 & 5.16 & -0.37 & -0.13 \\
\hline$(2 \sqrt{3} \times 3)-\mathrm{Hg} / \mathrm{Cu}(111)$ & 0.083 & -0.52 & 2.75 & 7.70 & 4.79 & -0.44 & -0.02 \\
\hline$(2 \sqrt{3} \times 3)-\mathrm{Hg} / \mathrm{Ni}(111)$ & 0.083 & -0.67 & 2.72 & 7.47 & 5.08 & -0.51 & 0.06 \\
\hline$(2 \sqrt{3} \times 3)-\mathrm{Hg} / \mathrm{Pd}(111)$ & 0.083 & -0.84 & 2.81 & 8.41 & 5.27 & -0.42 & -0.15 \\
\hline$(2 \sqrt{3} \times 3)-\mathrm{Hg} / \mathrm{Pt}(111)$ & 0.083 & -0.75 & 2.86 & 8.44 & 5.70 & -0.61 & -0.22 \\
\hline$p(2 \times 2)-\mathrm{Hg} / \mathrm{Ag}(111)$ & 0.25 & -0.36 & 3.01 & 5.88 & 4.47 & -0.38 & -0.02 \\
\hline$p(2 \times 2)-\mathrm{Hg} / \mathrm{Au}(111)$ & 0.25 & -0.38 & 3.01 & 5.90 & 5.27 & -0.76 & -0.12 \\
\hline$p(2 \times 2)-\mathrm{Hg} / \mathrm{Cu}(111)$ & 0.25 & -0.53 & 2.78 & 5.14 & 4.84 & -0.59 & 0.00 \\
\hline$p(2 \times 2)-\mathrm{Hg} / \mathrm{Ni}(111)$ & 0.25 & -0.64 & 2.74 & 4.98 & 5.09 & -0.82 & -0.03 \\
\hline$p(2 \times 2)-\mathrm{Hg} / \mathrm{Pd}(111)$ & 0.25 & -0.81 & 2.83 & 5.61 & 5.31 & -0.84 & -0.12 \\
\hline$p(2 \times 2)-\mathrm{Hg} / \mathrm{Pt}(111)$ & 0.25 & -0.68 & 2.88 & 5.62 & 5.67 & -1.06 & -0.18 \\
\hline$(\sqrt{3} \times \sqrt{3}) R 30^{\circ}-\mathrm{Hg} / \mathrm{Ag}(111)$ & 0.333 & -0.31 & 3.06 & 5.08 & 4.43 & -0.35 & -0.01 \\
\hline$(\sqrt{3} \times \sqrt{3}) R 30^{\circ}-\mathrm{Hg} / \mathrm{Au}(111)$ & 0.333 & -0.32 & 3.05 & 5.09 & 5.14 & -0.59 & -0.09 \\
\hline$(\sqrt{3} \times \sqrt{3}) R 30^{\circ}-\mathrm{Hg} / \mathrm{Ci}(111)$ & 0.333 & -0.48 & 2.82 & 4.43 & 4.74 & -0.56 & -0.02 \\
\hline$(\sqrt{3} \times \sqrt{3}) R 30^{\circ}-\mathrm{Hg} / \mathrm{Ni}(111)$ & 0.333 & -0.61 & 2.76 & 4.30 & 5.06 & -0.80 & 0.01 \\
\hline$(\sqrt{3} \times \sqrt{3}) R 30^{\circ}-\mathrm{Hg} / \mathrm{Pd}(111)$ & 0.333 & -0.80 & 2.83 & 4.84 & 5.28 & -0.88 & -0.11 \\
\hline$(\sqrt{3} \times \sqrt{3}) R 30^{\circ}-\mathrm{Hg} / \mathrm{Pt}(111)$ & 0.333 & -0.67 & 2.89 & 4.85 & 5.70 & -1.16 & -0.15 \\
\hline$p(2 \times 2)-\mathrm{Hg} / \mathrm{Ag}(111)$ & 0.5 & -0.37 & 3.09 & 3.40 & 4.47 & -0.25 & 0.01 \\
\hline$p(2 \times 2)-\mathrm{Hg} / \mathrm{Au}(111)$ & 0.5 & -0.35 & 3.11 & 3.41 & 5.29 & -0.66 & -0.08 \\
\hline$p(2 \times 2)-\mathrm{Hg} / \mathrm{Cu}(111)$ & 0.5 & -0.51 & 2.87 & 2.97 & 4.85 & -0.32 & 0.02 \\
\hline$p(2 \times 2)-\mathrm{Hg} / \mathrm{Ni}(111)$ & 0.5 & -0.61 & 2.75 & 2.88 & 5.08 & -0.50 & 0.00 \\
\hline$p(2 \times 2)-\mathrm{Hg} / \mathrm{Pd}(111)$ & 0.5 & -0.81 & 2.85 & 3.24 & 5.31 & -0.91 & -0.07 \\
\hline$p(2 \times 2)-\mathrm{Hg} / \mathrm{Pt}(111)$ & 0.5 & -0.69 & 2.92 & 3.25 & 5.68 & -1.05 & -0.12 \\
\hline
\end{tabular}

platinum as on palladium. Silver and gold compare to one another in an analogous way; their binding energies are similar to one another (although much smaller than those of platinum and palladium) but the work function change on gold is about double the size of the work function change on silver.

\section{A. Hg on (111) metal surfaces}

Adsorption of $\mathrm{Hg}$ on (111) metal surfaces was calculated for four overlayers ranging from $0.0833 \mathrm{ML}$ to $0.5 \mathrm{ML}$. The results for mercury adsorption on (111) metal surfaces are presented in Table II and the overlayers are represented in Fig. 1. For each overlayer, the mercury-mercury distances $(\mathrm{Hg}-\mathrm{Hg})$ result from the imposition of periodic boundary conditions and therefore are a direct function of the size of the lattice constant for any given overlayer pattern. The $(2 \sqrt{3} \times 3)-\mathrm{Hg} / \mathrm{M}(111) 0.0833 \mathrm{ML}$ overlayer is the largest supercell considered in this study. Distances between neighboring adsorbed mercury atoms on this overlayer are between $7.47 \AA$ (on the nickel surface) and $8.85 \AA$ (on the gold surface); these separations are large enough such that the results should be dominated by $\mathrm{Hg}$-metal effects, rather than $\mathrm{Hg}-\mathrm{Hg}$ effects. As can be observed in Fig. 1, the $p(2$ $\times 2)-\mathrm{Hg} / \mathrm{M}(111) \quad 0.25 \quad \mathrm{ML}, \quad(\sqrt{3} \times \sqrt{3}) R 30^{\circ}-\mathrm{Hg} / \mathrm{M}(111)$ $0.333 \mathrm{ML}$, and $p(2 \times 2)-\mathrm{Hg} / \mathrm{M}(111) 0.5 \mathrm{ML}$ all have $\mathrm{Hg}$ atoms situated in a symmetric hexagonal pattern [although in the $p(2 \times 2)-\mathrm{Hg} / \mathrm{M}(111) 0.5 \mathrm{ML}$ overlayer, there is not an $\mathrm{Hg}$ atom in the center of each hexagon, while for the former overlayers, there is]. The supercell used for the $p(2$ $\times 2)-\mathrm{Hg} / \mathrm{M}(111) \quad 0.25 \mathrm{ML}$ overlayer and the $p(2$ $\times 2)-\mathrm{Hg} / \mathrm{M}(111) 0.5 \mathrm{ML}$ overlayer is the same, with one and two $\mathrm{Hg}$ atoms included, respectively, for the overlayers. The calculations predict binding of $\mathrm{Hg}$ to all six metals in all four overlayers to be thermodynamically favored. Adsorption of mercury is predicted to cause a decrease in the work function on all six metals and for all the overlayers, with the most dramatic changes occurring on platinum.

\section{B. Hg on (001) metal surfaces}

Adsorption of mercury on the (001) metal surfaces was investigated for three overlayers with coverages ranging from 0.125 to $1.0 \mathrm{ML}$. The results for the (001) surfaces are presented in Table III and the overlayers are represented in Fig. 2. In contrast to the overlayers on the (111) surfaces, the 
(a)

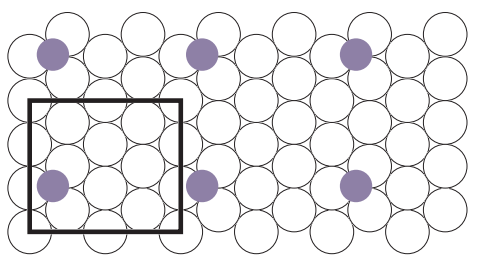

(b)

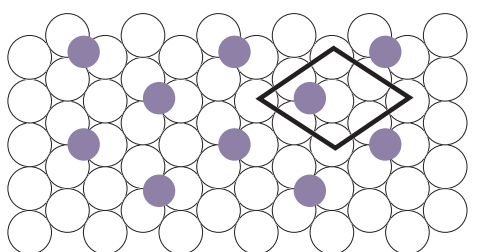

(c)

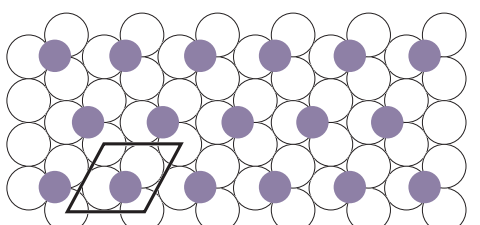

(d)

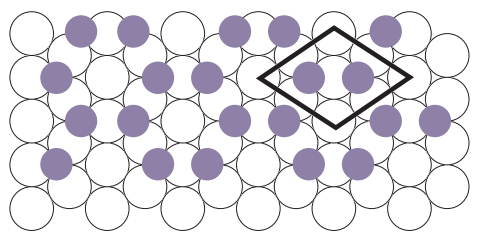

FIG. 1. (Color online) $\mathrm{Hg}$ overlayers on fcc (111) metal surfaces: (a) $(2 \sqrt{3} \times 3)-\mathrm{Hg} / M(111)$ overlayer, $0.083 \mathrm{ML}$; (b) $p(2$ $\times 2)-\mathrm{Hg} / M(111) \quad$ overlayer, $0.25 \quad \mathrm{ML} ; \quad$ (c) $\quad(\sqrt{3}$ $\times \sqrt{3}) R 30^{\circ}-\mathrm{Hg} / M(111) \quad$ overlayer, $0.333 \mathrm{ML} ; \quad$ (d) $p(2$ $\times 2)-\mathrm{Hg} / M(111)$ overlayer, 0.50 ML. Open circles represent substrate atoms and solid circles represent adsorbed mercury atoms (in threefold hollow positions). Refer to Table II.

$\mathrm{Hg}$ atoms on the (001) surface are arranged in rectilinear patterns. The $c(4 \times 4)-\mathrm{Hg} / \mathrm{M}(001)$ overlayer $(0.125 \mathrm{ML})$ is the lowest coverage modeled on the (001) surface. $\mathrm{Hg}-\mathrm{Hg}$ distances are 7.04-8.35 $\AA$ on the surface; these distances are large enough that results for this overlayer should be dominated by $\mathrm{Hg}$-metal interactions.

For any given metal, the binding of mercury is stronger on the (001) surface as compared to the (111) surface (with two exceptions noted below). On the (111) surface, mercury is bound in the threefold hollow sites, while on the (001) surface, it is bound in the fourfold hollow sites, giving the adsorbed mercury a (favorable) higher coordination number on the (001) surfaces. Absorption of $\mathrm{Hg}$ on all six metals is thermodynamically favored except for the $c(1$ $\times 1)-\mathrm{Hg} / \mathrm{Cu}(001)$ and $c(1 \times 1)-\mathrm{Hg} / \mathrm{Ni}(001)$ overlayers. These model a full monolayer on metals in which the relatively small lattice constants bring the adsorbed $\mathrm{Hg}$ atoms too close together on the surface, leading to repulsive $\mathrm{Hg}-\mathrm{Hg}$ interactions.

The calculated change in work function upon adsorption of mercury is negative for all overlayers on all six metal (001) substrates except for the $c(2 \times 2)$ and $c(1 \times 1)$ overlayers on Ag.

\section{DISCUSSION}

\section{A. Magnitude of the interaction with metal surfaces}

The magnitude of the interaction between mercury and the metal surface is more strongly influenced by the identity of the substrate than any other factor considered here (such as the distance between neighboring $\mathrm{Hg}$ atoms or the amount of charge that is transferred from the mercury atom to the metal surface). All the mercury overlayers examined here are thermodynamically favored with the exception only of two overlayers in which mercury atoms are forced to reside within a distance of $2.6 \AA$ of one another.

The results of this study indicate a general ordering of the metal surfaces with increasing reactivity towards mercury according to $\mathrm{Ag}<\mathrm{Au}<\mathrm{Cu}<\mathrm{Ni}<\mathrm{Pt}<\mathrm{Pd}$. This is in agreement with the results of Soverna and colleagues, with the exception of $\mathrm{Ni}$, which they found interacted with mercury more weakly than Au. Soverna and colleagues pointed out that oxygen may have been present on the surface of the metal under the conditions of their experiment and this could have caused the difference.

Quantitative agreement between the DFT results and experimental data is good for the $c(4 \times 4)-\mathrm{Hg} / \mathrm{Cu}(001)$ and $c(2 \times 2)-\mathrm{Hg} / \mathrm{Cu}(001)$ overlayers, for which the theoretical (experimental) $\quad E_{a d s}$ are $-0.67 \quad(-0.70)$ and -0.71 $(-0.74) \mathrm{eV}$, respectively. ${ }^{32}$ Agreement for the $c(1$ $\times 1)-\mathrm{Hg} / \mathrm{Ag}(001)$ surface is fair, with theoretical (experimental) $E_{a d s}$ of $-0.30(-0.63) \mathrm{eV} .{ }^{32}$ The agreement for the nickel (001) and (111) surface overlayers is poor overall. The theoretical (experimental) $E_{\text {ads }}$ for the $(\sqrt{3}$

(a)

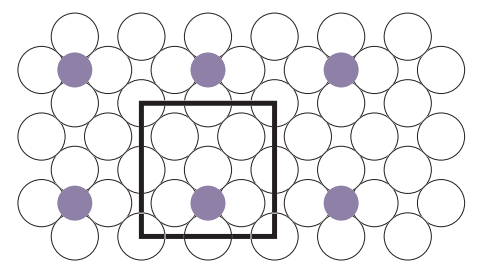

(b)
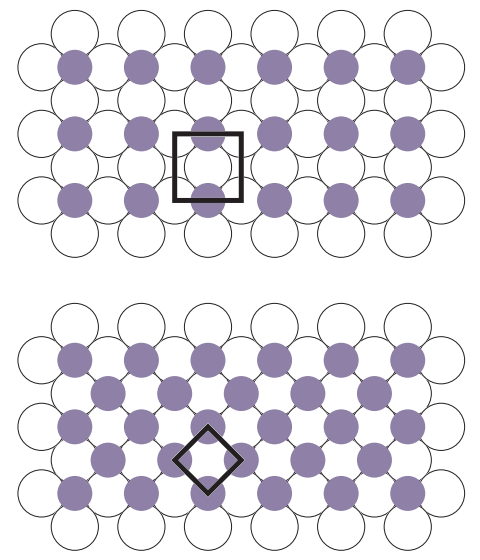

FIG. 2. (Color online) Models for Hg adsorption on fcc (001) metal surfaces: (a) $c(4 \times 4)-\mathrm{Hg} / M(001)$ overlayer, $0.125 \mathrm{ML}$; (b) $c(2 \times 2)-\mathrm{Hg} / M(001)$ overlayer, $0.5 \mathrm{ML}$; (c) $c(1 \times 1)-\mathrm{Hg} / M(001)$ overlayer, 1.0 ML. Open circles represent substrate atoms and solid circles represent adsorbed mercury atoms (in fourfold hollow positions). Refer to Table III. 
TABLE III. Hg adsorption on (001) metal surfaces on hollow sites: $\theta$ denotes coverage, $E_{a d s}$ denotes binding energy, $M-\mathrm{Hg}$ and $\mathrm{Hg}-\mathrm{Hg}$ denote distances between adsorbed $\mathrm{Hg}$ and substrate or neighboring $\mathrm{Hg}$ atoms, respectively, $\Phi$ is the calculated work function of the bare metal, and $\Delta \Phi$ and $\Delta Q$ are the adsorptioninduced changes in work function and charge on $\mathrm{Hg}$.

\begin{tabular}{lccccccr}
\hline \hline & $\begin{array}{c}\theta \\
\text { Overlayer }\end{array}$ & $\begin{array}{c}E_{a d s} \\
(\mathrm{ML})\end{array}$ & $\begin{array}{c}M-\mathrm{Hg} \\
(\AA)\end{array}$ & $\begin{array}{c}\mathrm{Hg}-\mathrm{Hg} \\
(\AA)\end{array}$ & $\begin{array}{c}\Phi \\
(\mathrm{eV})\end{array}$ & $\begin{array}{c}\Delta \Phi \\
(\mathrm{eV})\end{array}$ & $\begin{array}{c}\Delta Q \\
(\text { a.u. })\end{array}$ \\
\hline$c(4 \times 4)-\mathrm{Hg} / \mathrm{Ag}(001)$ & 0.125 & -0.50 & 3.01 & 8.32 & 4.21 & -0.09 & 0.01 \\
$c(4 \times 4)-\mathrm{Hg} / \mathrm{Au}(001)$ & 0.125 & -0.61 & 2.94 & 8.35 & 5.04 & -0.28 & -0.09 \\
$c(4 \times 4)-\mathrm{Hg} / \mathrm{Cu}(001)$ & 0.125 & -0.67 & 2.78 & 7.26 & 4.55 & -0.32 & 0.03 \\
$c(4 \times 4)-\mathrm{Hg} / \mathrm{Ni}(001)$ & 0.125 & -0.82 & 2.73 & 7.04 & 4.89 & -0.45 & 0.02 \\
$c(4 \times 4)-\mathrm{Hg} / \mathrm{Pd}(001)$ & 0.125 & -1.10 & 2.83 & 7.93 & 5.09 & -0.35 & -0.05 \\
$c(4 \times 4)-\mathrm{Hg} / \mathrm{Pt}(001)$ & 0.125 & -1.09 & 2.83 & 7.95 & 5.65 & -0.67 & -0.18 \\
$c(2 \times 2)-\mathrm{Hg} / \mathrm{Ag}(001)$ & 0.5 & -0.51 & 3.02 & 4.16 & 4.17 & 0.03 & 0.06 \\
$c(2 \times 2)-\mathrm{Hg} / \mathrm{Au}(001)$ & 0.5 & -0.51 & 3.00 & 4.17 & 5.22 & -0.90 & -0.10 \\
$c(2 \times 2)-\mathrm{Hg} / \mathrm{Cu}(001)$ & 0.5 & -0.71 & 2.80 & 3.63 & 4.71 & -0.58 & 0.04 \\
$c(2 \times 2)-\mathrm{Hg} / \mathrm{Ni}(001)$ & 0.5 & -0.81 & 2.77 & 3.52 & 4.93 & -0.60 & 0.04 \\
$c(2 \times 2)-\mathrm{Hg} / \mathrm{Pd}(001)$ & 0.5 & -1.08 & 2.83 & 3.97 & 5.07 & -0.80 & -0.03 \\
$c(2 \times 2)-\mathrm{Hg} / \mathrm{Pt}(001)$ & 0.5 & -0.97 & 2.85 & 3.98 & 5.59 & -1.42 & -0.04 \\
$c(1 \times 1)-\mathrm{Hg} / \mathrm{Ag}(001)$ & 1.0 & -0.30 & 3.30 & 2.94 & 4.08 & 0.04 & 0.01 \\
$c(1 \times 1)-\mathrm{Hg} / \mathrm{Au}(001)$ & 1.0 & -0.35 & 3.39 & 2.95 & 5.11 & -0.76 & -0.07 \\
$c(1 \times 1)-\mathrm{Hg} / \mathrm{Cu}(001)$ & 1.0 & 0.27 & 3.14 & 2.57 & 4.66 & -0.59 & 0.01 \\
$c(1 \times 1)-\mathrm{Hg} / \mathrm{Ni}(001)$ & 1.0 & 0.55 & 2.99 & 2.49 & 4.90 & -0.61 & 0.00 \\
$c(1 \times 1)-\mathrm{Hg} / \mathrm{Pd}(001)$ & 1.0 & -0.67 & 2.95 & 2.80 & 5.05 & -0.66 & -0.06 \\
$c(1 \times 1)-\mathrm{Hg} / \mathrm{Pt}(001)$ & 1.0 & -0.58 & 3.05 & 2.81 & 5.58 & -0.90 & -0.10 \\
\hline \hline
\end{tabular}

$\times \sqrt{3}) R 30^{\circ}-\mathrm{Hg} / \mathrm{Ni}(111)$ and $p(2 \times 2)-\mathrm{Hg} / \mathrm{Ni}(001)$ overlayers are $-0.61(-2.07)$ and $-0.61(-0.83) \mathrm{eV}$, respectively. ${ }^{31}$ The theoretical (experimental) $E_{a d s}$ for the $c(2$ $\times 2)-\mathrm{Hg} / \mathrm{Ni}(001)$ overlayer is $-0.81(-1.71) \mathrm{eV} \cdot{ }^{28}$ Overall, the DFT results using the PBE functional give values for $E_{a d s}$ that are low in comparison with experiment. If one compares the thermochromatic studies of mercury adsorption of Soverna et al. with the most strongly bound overlayer considered in this study $[c(4 \times 4)-\mathrm{Hg} / \mathrm{M}(001)]$, it appears the PBE functional is underestimating the strength of the interaction by $0.1-0.4 \mathrm{eV} .{ }^{35}$ Use of the LDA functional would provide stronger interactions; however, judging by the results presented in Table I, the interaction would almost certainly be overestimated by about the same amount.

\section{B. Site preference}

Using standing x-ray wave-field absorption experiments, Prince et al. deduced that $\mathrm{Hg}$ atoms are bound at the bridge site on the $c(2 \times 2)-\mathrm{Hg} / \mathrm{Ni}(001)$ surface ${ }^{30}$ However, these authors assumed an Hg-Ni distance of $2.63 \AA$. They point out that adsorption at the hollow sites would be consistent with their data if the $\mathrm{Hg}-\mathrm{Ni}$ bond were $\approx 2.95 \pm 0.10 \AA$; the $\mathrm{Hg}-\mathrm{Ni}$ distance for this overlayer that is determined by the DFT calculations is $2.77 \AA$. Subsequently, Poulsen et al. used transmission channeling to determine that adsorption of $\mathrm{Hg}$ on $\mathrm{Ni}(001)$ below $0.5 \mathrm{ML}$ occurs at the four-fold hollow sites at a height of $2.25 \pm 0.10 \AA .^{34}$ The DFT results presented here are consistent with this result. As can be seen in
Table I, the energy ordering of the high-symmetry surface sites remains consistent whether the LDA, PW91, or PBE functional is used.

The magnitude of the interactions and the energy ordering of the high-symmetry sites on metal surfaces presented in this work differ from those reported for $\mathrm{Hg}$ on $\mathrm{Au}(001)$ by Sarpe-Tudoran and colleagues, whose relativistic DFT calculations were performed on cluster models and embedded clusters. ${ }^{27}$ Sarpe-Tudoran et al. report the bridge site as the lowest-energy binding site for mercury on $\mathrm{Au}(001)$, while in the present study, the hollow site was found to be more thermodynamically favorable for $\mathrm{Hg}$ on all six metal surfaces. Sarpe-Tudoran et al. point out that, due to the extreme demands of the relativistic calculations, they were not able to ensure that the results were converged with respect to cluster size. In the present work, the slab models do not suffer from size limitations, but relativistic effects are accounted for only in the use of the PAW pseudopotentials, which are based on scalar-relativistic all-electron calculations. Differences in the energy ordering of high-symmetry surface sites may also be due to limitations of the DFT formalism. There have been cases in which the site preference for adsorption on metals has been incorrectly predicted by DFT, possibly as a result of the incorrect energies of unoccupied bands associated with adsorbates in cases where back-donation from the metal to the adsorbate is important. ${ }^{58,59}$

\section{Lateral $\mathrm{Hg}-\mathrm{Hg}$ interactions}

As coverage is increased and $\mathrm{Hg}$ adatoms are brought closer to one another on the metal surfaces, there is evidence 


\section{Hg on Ag vs Pt}

$\mathrm{Hg}$ on $\mathrm{Ag}$

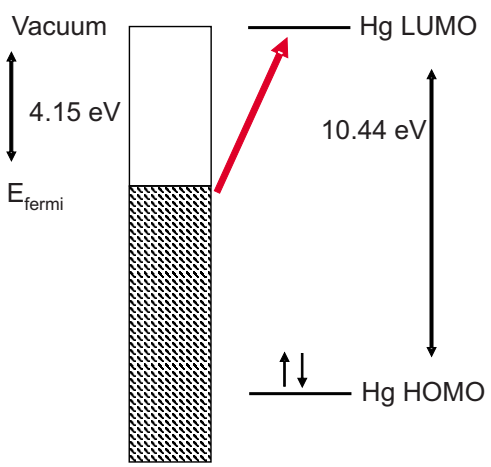

$\mathrm{Hg}$ on $\mathrm{Pt}$

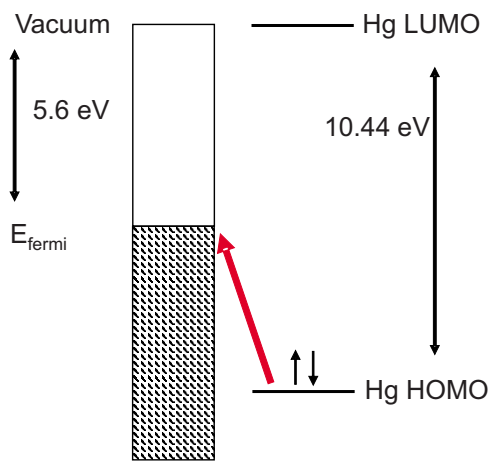

FIG. 3. (Color online) Koopmans' theorem interpretation for the relationship between the magnitude of the work function change and the value of the work function for the bare metal.

for first attractive and then repulsive interactions. Attractive $\mathrm{Hg}-\mathrm{Hg}$ interactions were proposed in order to explain experimental observations in several previous works. ${ }^{28,31,32}$ The current DFT results are consistent with the existence of weak attractive $\mathrm{Hg}-\mathrm{Hg}$ interactions. For example, in going from the $c(4 \times 4)$ to the $c(2 \times 2)$ phase on the $\mathrm{Cu}(001)$ surface, there is a small energetic advantage of $-0.04 \mathrm{eV}$. This corresponds to bringing surface $\mathrm{Hg}$ atoms from a separation of 7.26 to $3.63 \AA$. This is very close to the $\mathrm{Hg}-\mathrm{Hg}$ separation in the gas-phase $\mathrm{Hg}_{2}$ dimer. ${ }^{60}$ The binding energy of the $\mathrm{Hg}_{2}$ dimer, as calculated using plane-wave DFT, is $\sim-0.033 \mathrm{eV}$ at an $\mathrm{Hg}-\mathrm{Hg}$ separation of $3.60 \AA$.

Strong short-range repulsive lateral $\mathrm{Hg}-\mathrm{Hg}$ interactions are consistent with the decrease in binding energy with increased coverage and with the result that the $c(1 \times 1)$ over-

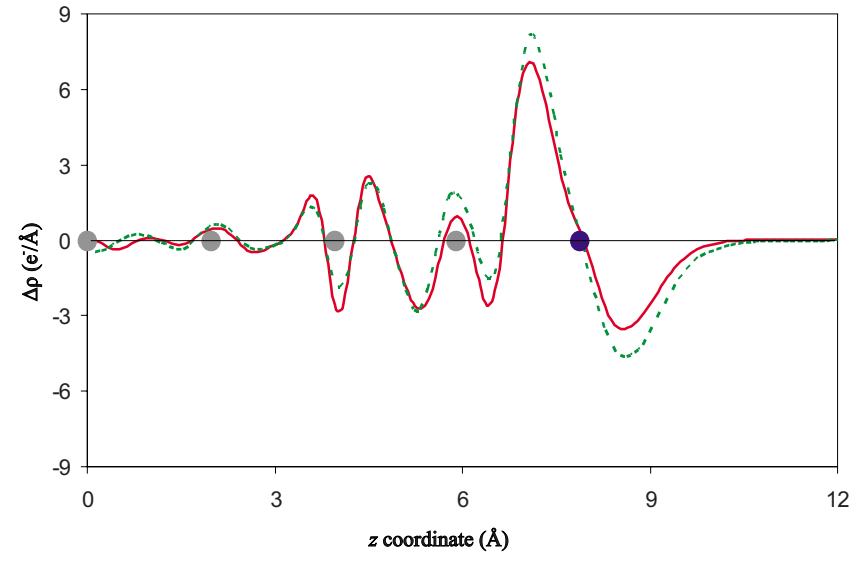

FIG. 4. (Color online) Adsorbate-induced charge density difference as a function of $z$ coordinate for the $c(4 \times 4)-\mathrm{Hg} / M(001)$ overlayer, $M=\mathrm{Pd}$, solid line (red); Pt, dashed line (green). Positive values indicate charge is accumulated upon adsorption while negative values indicate loss of charge upon $\mathrm{Hg}$ adsorption. The location of the adsorbed $\mathrm{Hg}$ atom is indicated by a dark (blue) dot; the locations of the layers of the substrate metal atoms are indicated by light (gray) dots. The vacuum region of the supercell has been omitted for clarity. layer is not thermodynamically favored on either $\mathrm{Cu}(001)$ or $\mathrm{Ni}(001)$ because these overlayers would require $\mathrm{Hg}-\mathrm{Hg}$ distances of less than $2.6 \AA$.

\section{Change in work function}

The adsorbate-induced change in work function is negative for every overlayer studied here with the exception of the $c(2 \times 2)-\mathrm{Hg} / \mathrm{Ag}(001)$ and $c(1 \times 1)-\mathrm{Hg} / \mathrm{Ag}(001)$ overlayers. The adsorbate-induced change in the work function is influenced by the change in the effective surface dipole. ${ }^{55}$ The surface dipole is affected by factors such as charge spillout and Smoluchowski smoothing, which tend to balance one another. For an electropositive adsorbate such as mercury,

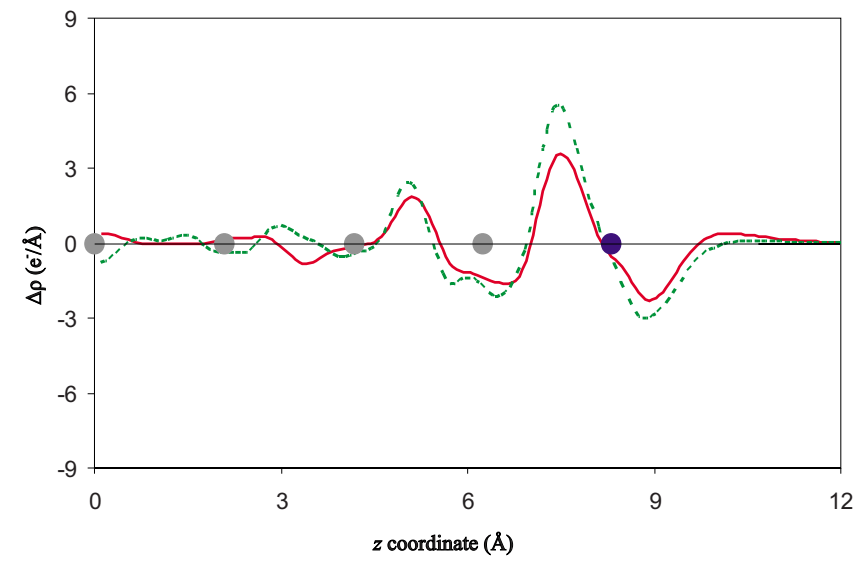

FIG. 5. (Color online) Adsorbate-induced charge density difference as a function of $z$ coordinate for the $c(4 \times 4)-\mathrm{Hg} / M(001)$ overlayer, $M=\mathrm{Ag}$, solid line (red); Au, dashed line (green). Positive values indicate charge is accumulated upon adsorption while negative values indicate loss of charge upon $\mathrm{Hg}$ adsorption. The location of the adsorbed $\mathrm{Hg}$ atom is indicated by a dark (blue) dot; the locations of the layers of the substrate metal atoms are indicated by light (gray) dots. The vacuum region of the supercell has been omitted for clarity. 
surface $\mathrm{Ag}$ atoms

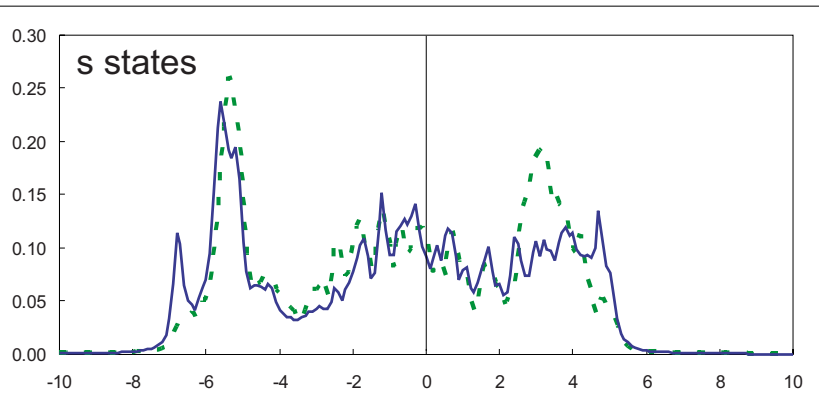

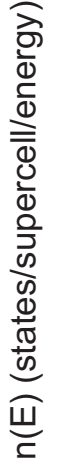
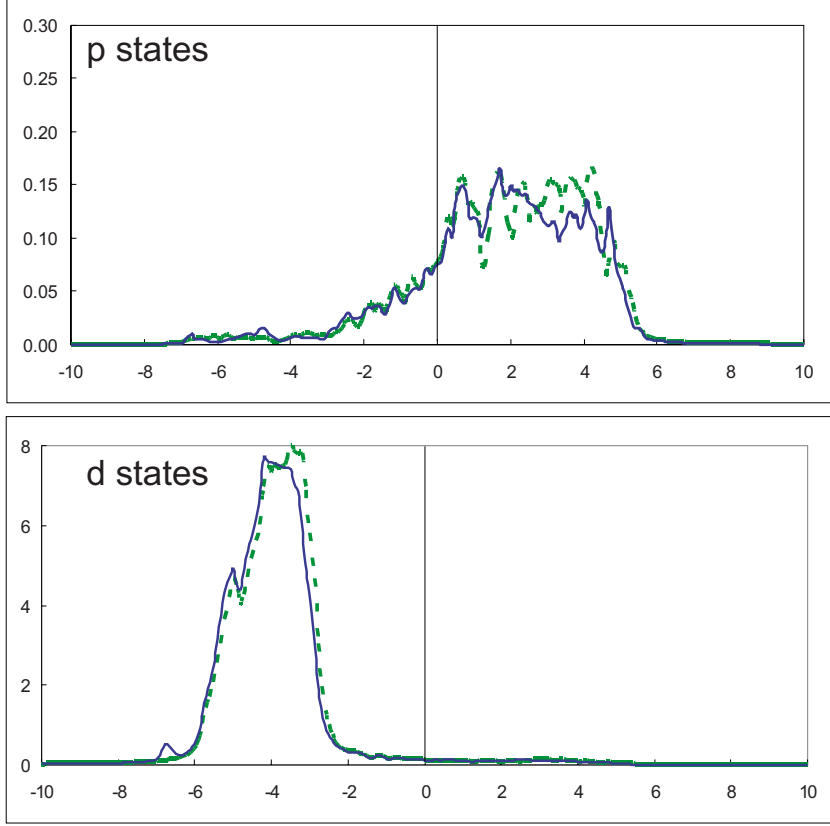

$\mathrm{Hg}$
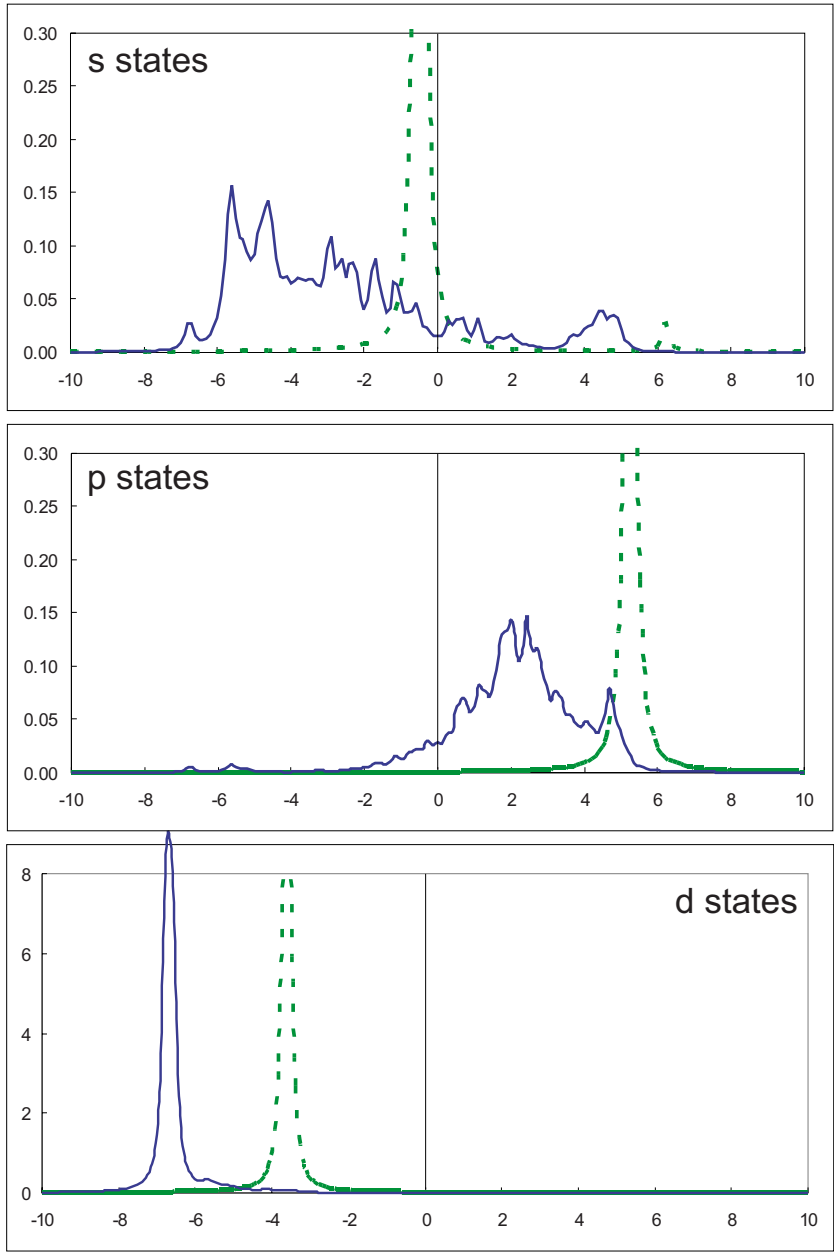

Energy $(\mathrm{eV})$

FIG. 6. (Color online) Site-projected density of states (states/atom/energy) for $\mathrm{Hg}$ on the $c(4 \times 4)-\mathrm{Hg} / \mathrm{Ag}(001)$ overlayer. The $s, p$, and $d$ states of the four metal surface atoms before adsorption (dotted green line) and after adsorption (solid blue line) are presented on the left. On the right are presented the $s, p$, and $d$ states for an isolated $\mathrm{Hg}$ atom (dotted green line) and $\mathrm{Hg}$ adsorbed in the fourfold hollow sites of the metal surface (solid blue line).

there is typically charge transfer from the adsorbate into the substrate, resulting in a decrease in the work function. It can be determined by examination of the data in Tables II and III that the adsorbate-induced change in work function is dramatic for mercury adsorption on the metals with larger work functions-e.g., Pd and Pt. A simple interpretation for this relation is possible via Koopmans' theorem. ${ }^{61,62}$ The electron affinity of mercury is nearly zero, so we can set the level of the $\mathrm{Hg}$ lowest unoccupied molecular orbital (LUMO) to the level of the vacuum for the metal surface. The $\mathrm{Hg}$ highest occupied molecular orbital (HOMO) then should be below the LUMO by approximately the amount of the ionization potential for mercury, which is $10.44 \mathrm{eV}$. In the case of metals having fairly large work functions such as $\mathrm{Pd}$ and $\mathrm{Pt}$, the energy difference between the HOMO and the Fermi level should be smaller than between the Fermi level and the LUMO, leading to charge transfer from the HOMO to the metal substrate. For metals with smaller work functions such as Ag, the energy difference between the Fermi level and the LUMO might be small enough to lead to charge transfer from the metal substrate into the LUMO of mercury. This is illustrated in Fig. 3. The values of $\Delta Q$ calculated via the Bader analysis are also consistent with this view, being typically most negative for the Pd and Pt overlayers.

\section{E. Charge density differences}

To investigate the changes in the charge density that result from the adsorption of mercury to the metal surfaces, the charge density difference along $z$ has been calculated. The plane-averaged charge density $\rho(z)$ is given by

$$
\rho(z)=\frac{1}{A} \int_{0}^{a_{1}} d x \int_{0}^{a_{2}} d y \rho(x, y, z),
$$

where $A$ is the surface area of the supercell, $a_{1}$ and $a_{2}$ are the supercell dimensions in $x$ and $y$, and $\rho(x, y, z)$ is the full 
surface Au atoms

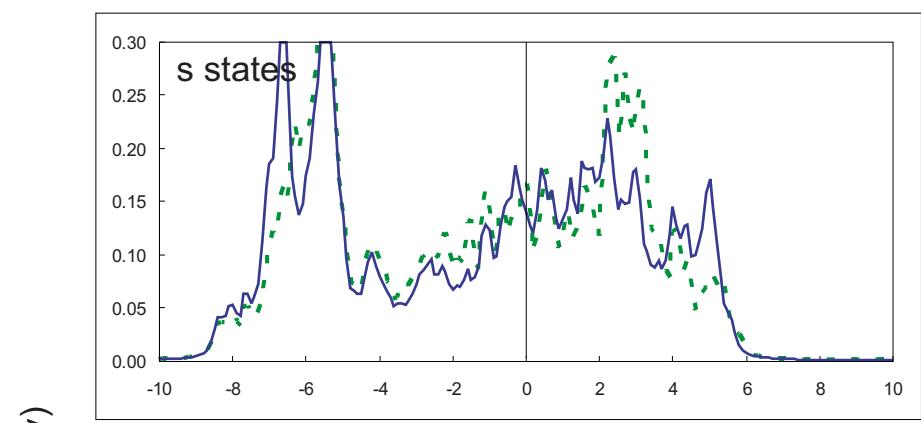

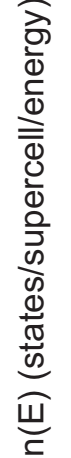
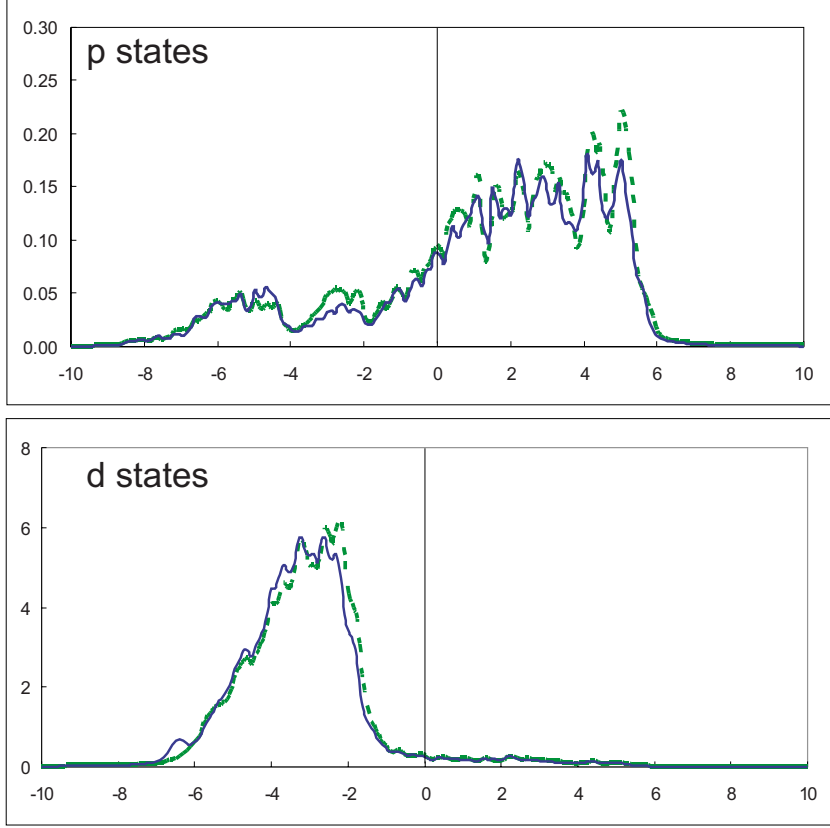

$\mathrm{Hg}$
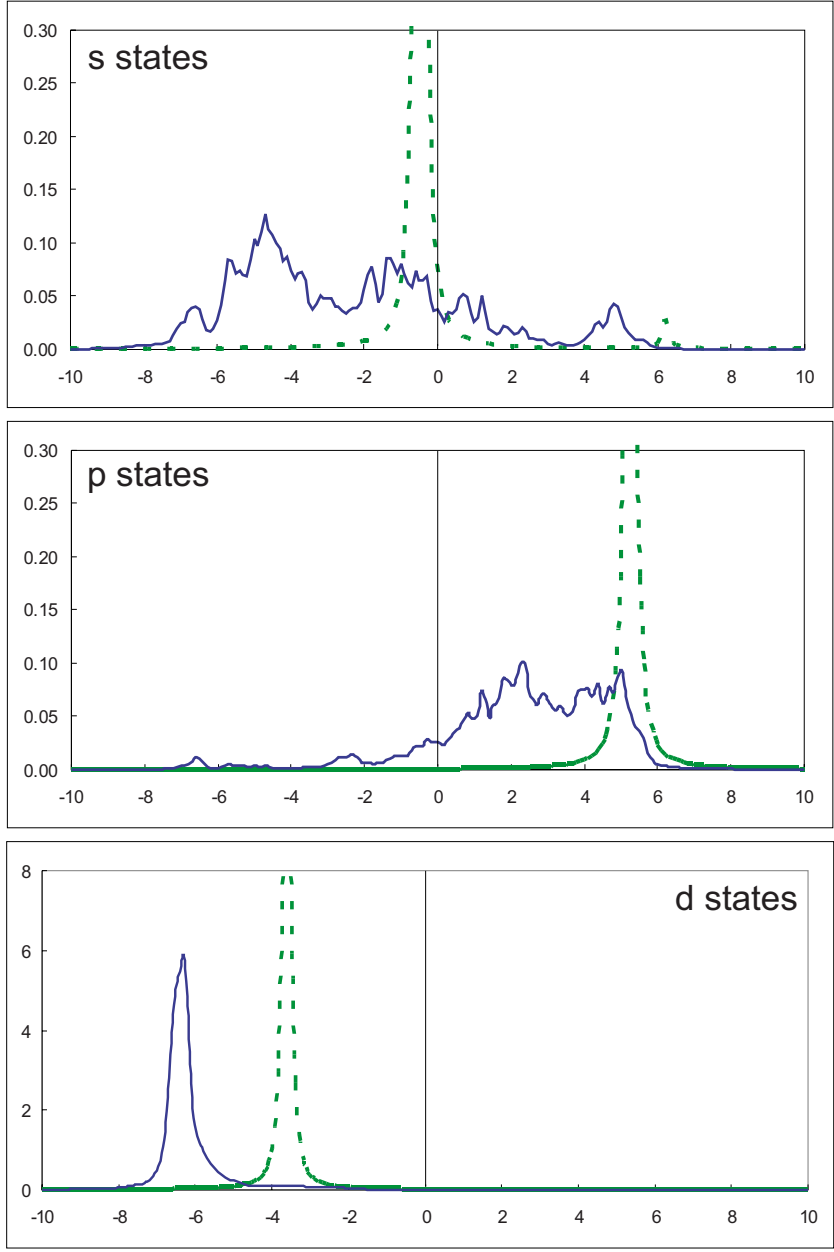

Energy $(\mathrm{eV})$

FIG. 7. (Color online) Site-projected density of states (states/atom/energy) for $\mathrm{Hg}$ on the $c(4 \times 4)-\mathrm{Hg} / \mathrm{Au}(001)$ overlayer. The $s, p$, and $d$ states of the four metal surface atoms before adsorption (dotted green line) and after adsorption (solid blue line) are presented on the left. On the right are presented the $s, p$, and $d$ states for an isolated $\mathrm{Hg}$ atom (dotted green line) and $\mathrm{Hg}$ adsorbed in the fourfold hollow sites of the metal surface (solid blue line).

charge density. The change in charge density upon adsorption of mercury has been calculated as

$$
\Delta \rho(z)=\rho(z)-\left[\rho_{\text {surf }}(z)+\rho_{\mathrm{Hg}}(z)\right]
$$

where $\rho(z)$ is the charge density along $z$ for the metal surface with $\mathrm{Hg}$ adsorbed, $\rho_{\text {surf }}(z)$ is the charge density along $z$ of the surface metal atoms, in the same positions but with the mercury atom removed, and $\rho_{\mathrm{Hg}}(z)$ is the charge density along $z$ of the $\mathrm{Hg}$ atom with the surface metal atoms removed. ${ }^{55}$

It is interesting to examine the similarities and differences for mercury adsorption to $\mathrm{Pd}$ and Pt. Binding energies for mercury are similar for these two substrates, but the change in the work function and the value of $\Delta Q$ is dramatically larger for Pt in all the overlayers considered. The lattice constants are quite similar with $a=3.965 \AA$ for $\mathrm{Pd}$ and $a$ $=3.977 \AA$ for Pt. For the $c(4 \times 4)-\mathrm{Hg} / M(001)$ overlayer, $E_{a d s}=-1.10(-1.09) \mathrm{eV}$ for $\mathrm{Pd}(\mathrm{Pt}) . \Delta \Phi=-0.35 \mathrm{eV}$ for $\mathrm{Pd}$, but for $\mathrm{Pt}$ it is $-0.67 \mathrm{eV}$, almost twice as large. The Bader charge analysis of the charge density shows that $\Delta Q=$ $-0.05 e$ for $\mathrm{Pd}$ while, for $\mathrm{Pt}, \Delta Q=-0.18 e$. In both cases, there is adsorbate-induced charge transfer from mercury to the metal, but for $\mathrm{Pt}$ it is several times larger.

The charge density difference upon adsorption of $\mathrm{Hg}$ on $\mathrm{Pd}$ and $\mathrm{Pt}$ is presented in Fig. 4. Positive values signify accumulation of charge upon adsorption; negative values indicate locations where charge density is lost upon Hg adsorption. The vacuum region of the supercell has been omitted for clarity. Changes in the charge density are most pronounced in the immediate region of the adsorbed $\mathrm{Hg}$ atom and the first two metal substrate layers. Adsorption of $\mathrm{Hg}$ induces a large transfer of charge from the region above the $\mathrm{Hg}$ to the region between the $\mathrm{Hg}$ atom and the first layer of the substrate metal. Around the first layer of the metal substrate there is an adsorbate-induced increase of charge density, while around the second layer there is an adsorbate- 
surface Pd atoms

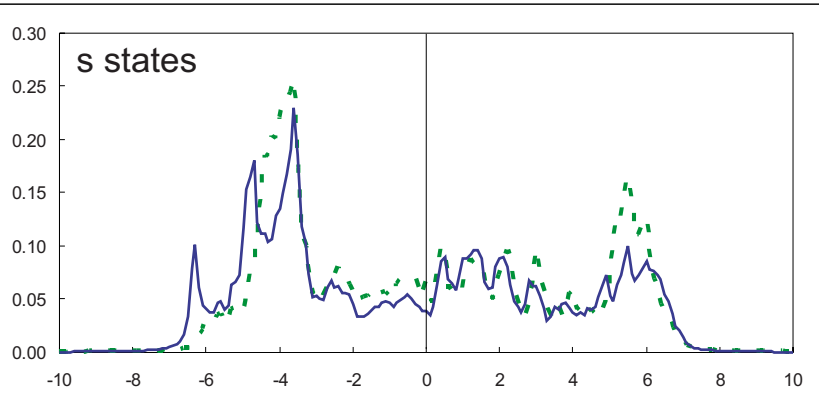

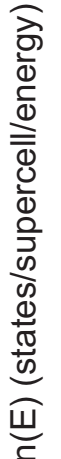
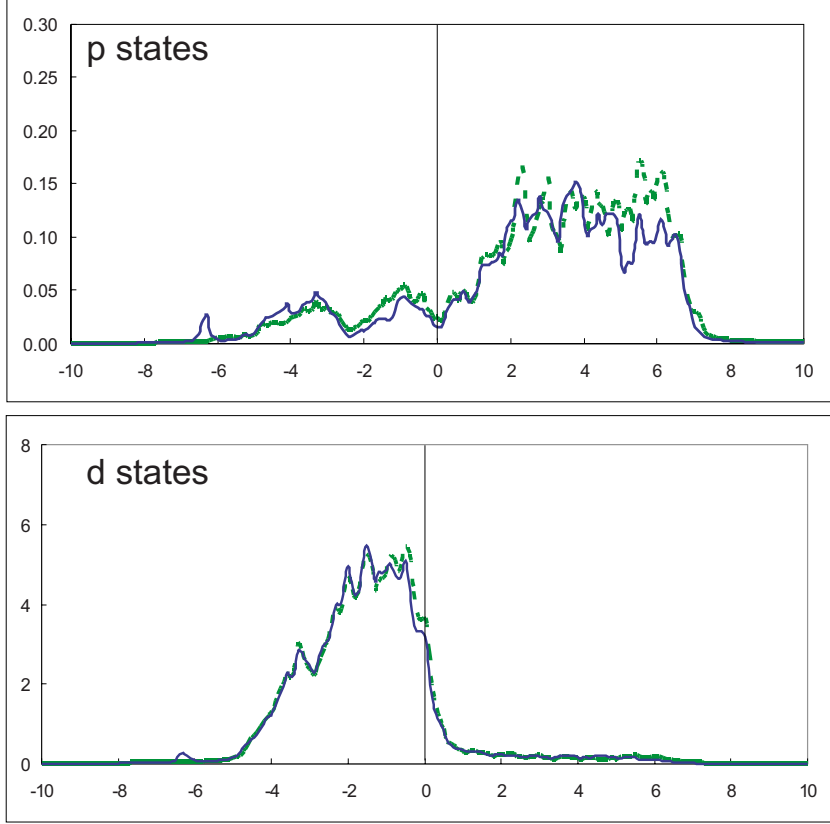

$\mathrm{Hg}$
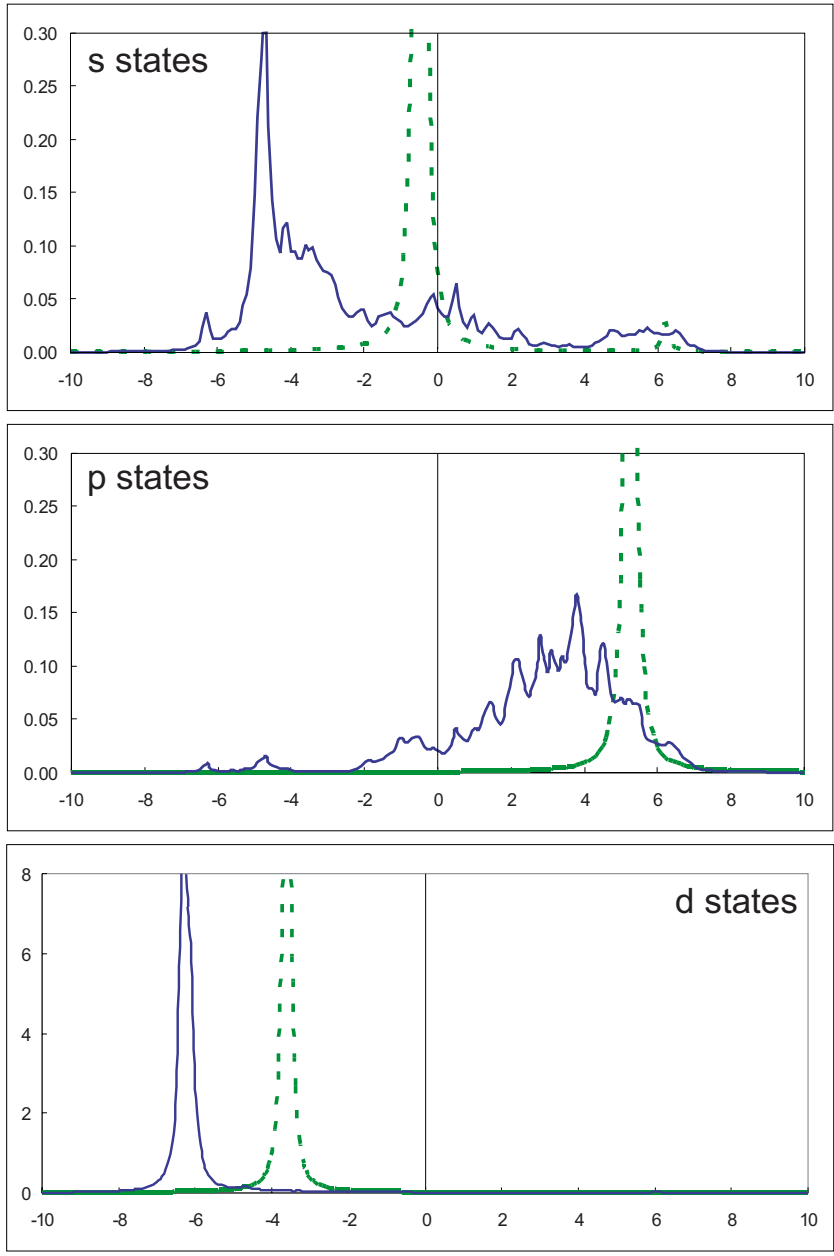

Energy $(\mathrm{eV})$

FIG. 8. (Color online) Site-projected density of states (states/atom/energy) for $\mathrm{Hg}$ on the $c(4 \times 4)-\mathrm{Hg} / \mathrm{Pd}(001)$ overlayer. The $s, p$, and $d$ states of the four metal surface atoms before adsorption (dotted green line) and after adsorption (solid blue line) are presented on the left. On the right are presented the $s, p$, and $d$ states for an isolated $\mathrm{Hg}$ atom (dotted green line) and $\mathrm{Hg}$ adsorbed in the fourfold hollow sites of the metal surface (solid blue line).

induced reduction of charge density. The oscillatory pattern of the charge density difference is much diminished by the third layer of the metal substrate. The overall pattern of the charge density difference for Pd and Pt is qualitatively similar, but the amount of charge transferred to the substrate from the $\mathrm{Hg}$ atom is greater in the case of Pt. This is consistent with the much greater $\Delta \Phi$ and $\Delta Q$ for Pt as compared with $\mathrm{Pd}$, despite the similarity in the value of $E_{a d s}$ for these two metal substrates.

Charge density differences for the $c(4 \times 4)-\mathrm{Hg} / \mathrm{M}(001)$, $M=\mathrm{Ag}, \mathrm{Au}$, overlayers are presented in Fig. 5. $E_{a d s}=$ $-0.50 \mathrm{eV}$ for $\mathrm{Ag}$ while, for $\mathrm{Au}, E_{a d s}=-0.61 \mathrm{eV}$. Thus mercury binds more weakly to both $\mathrm{Ag}$ and $\mathrm{Au}$ in contrast with $\mathrm{Pd}$ and Pt. The change in the work function and the values of $\Delta Q$ for $\mathrm{Ag}(\mathrm{Au})$ are $-0.09(-0.28) \mathrm{eV}$ and $+0.01 e(-0.09 e)$, respectively. Examination of the charge density differences reveals that charge is transferred from the region above the mercury to the region between the mercury and the first sub- strate layer, but overall the charge transfer is not as dramatic as what was observed for Pd and Pt. Another difference is that charge is lost from the area around the first metal substrate $\mathrm{Ag}$ and $\mathrm{Au}$ atoms, in contrast to $\mathrm{Pd}$ and $\mathrm{Pt}$, where charge was gained around the first layer substrate metal atoms. The accumulation of charge is mostly in the region between the adsorbate and the surface. It is also interesting to note that there is a small accumulation of charge in the region approximately $2-3 \AA$ above the mercury atom, which would be consistent with charge transfer into the LUMO of the mercury atom as suggested by the Koopmans' theorem interpretation. This is more pronounced for $\mathrm{Ag}$ than for $\mathrm{Au}$, which is consistent with the fact that the work function for $\mathrm{Ag}$ is smaller than that of Au.

\section{F. Partial density of states}

In order to examine the partial density of states (PDOS), the wave functions have been projected onto spherical har- 
surface Pt atoms

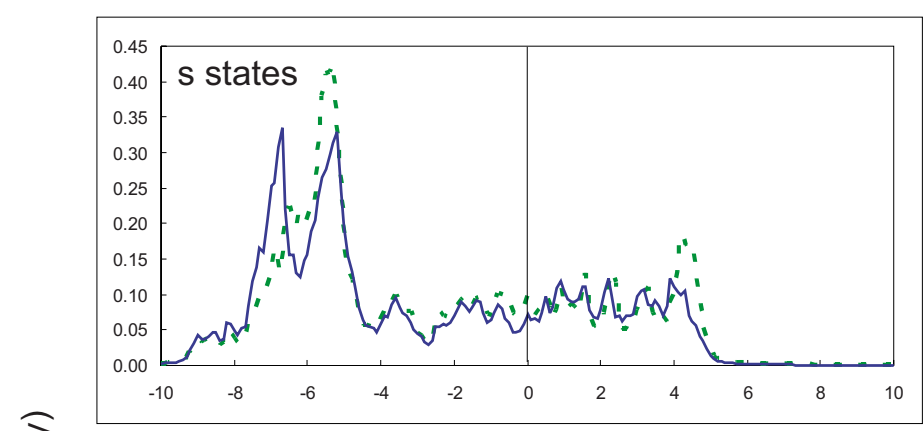

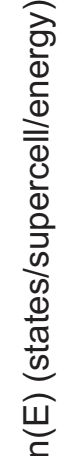
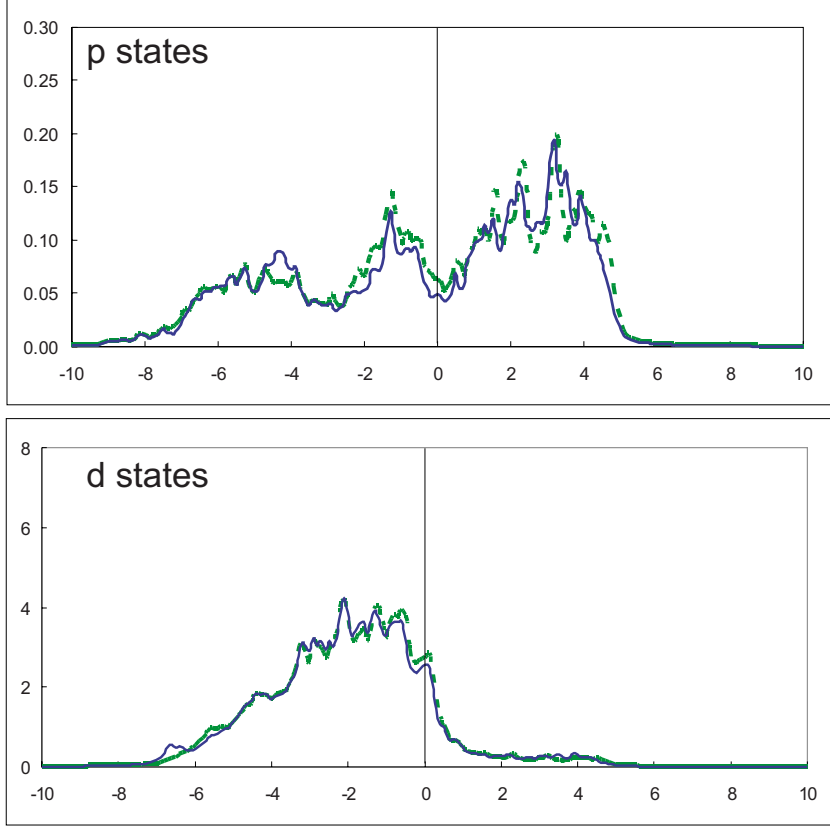

$\mathrm{Hg}$
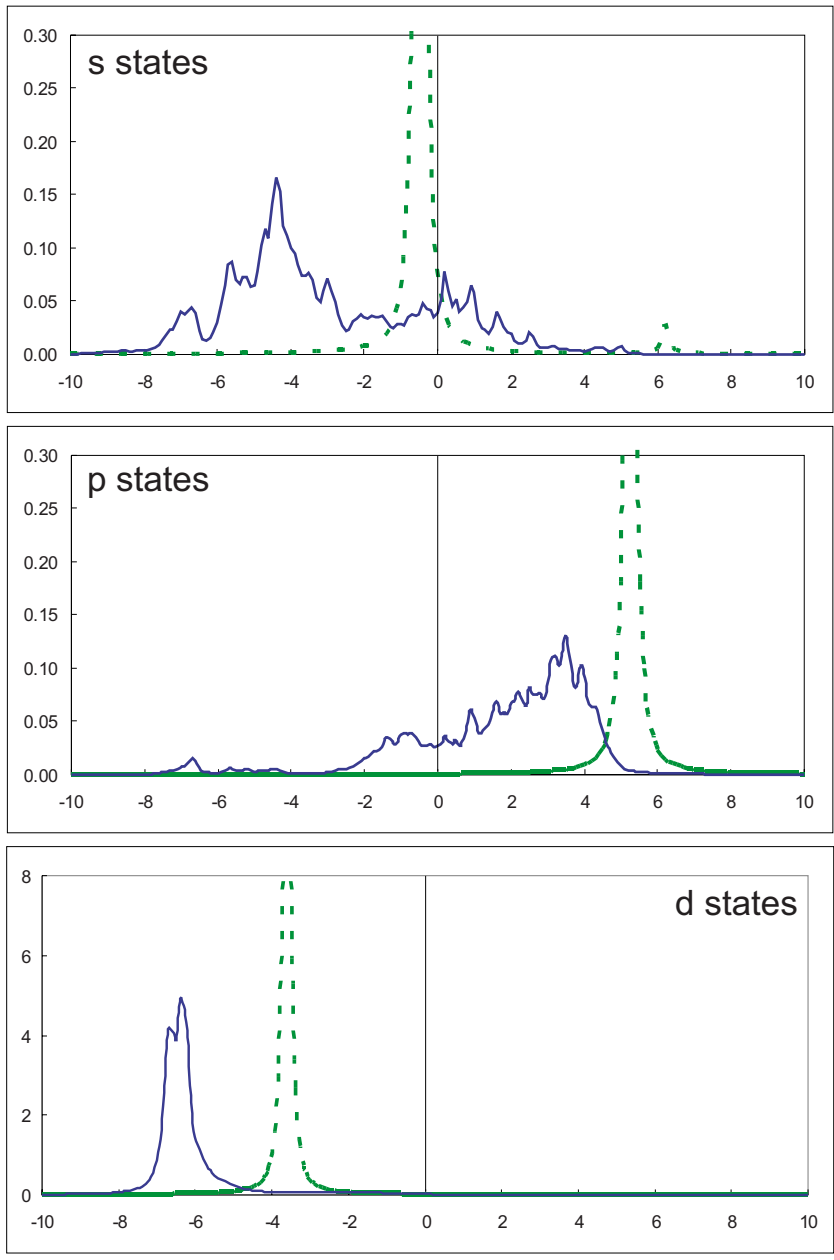

Energy $(\mathrm{eV})$

FIG. 9. (Color online) Site-projected density of states (states/atom/energy) for $\mathrm{Hg}$ on the $c(4 \times 4)-\mathrm{Hg} / \mathrm{Pt}(001)$ overlayer. The $s, p$, and $d$ states of the four metal surface atoms before adsorption (dotted green line) and after adsorption (solid blue line) are presented on the left. On the right are presented the $s, p$, and $d$ states for an isolated $\mathrm{Hg}$ atom (dotted green line) and $\mathrm{Hg}$ adsorbed in the fourfold hollow sites of the metal surface (solid blue line).

monics centered on the $\mathrm{Hg}$ atom and the four metal substrate atoms that form the fourfold hollow site for the $\mathrm{Hg}$ adsorption for the $c(4 \times 4)-\mathrm{Hg} / M(001)$ overlayer, $M=\mathrm{Ag}, \mathrm{Au}, \mathrm{Pd}$, and $\mathrm{Pt}$ overlayers. The partial density of states are presented in Figs. 6-9.

The DOS of the isolated $\mathrm{Hg}$ atom [calculated in a $(20 \AA)^{3}$ supercell with periodic boundary conditions] is characterized by well-defined $d$ and $s$ states near -3.6 and $-0.5 \mathrm{eV}$, respectively, and an (unfilled) $p$ state near $5.3 \mathrm{eV}$. After adsorption on the metal surfaces, the $s$ and $p$ states are markedly broadened and lowered, indicating strong interactions with the metal. The $p$ states after adsorption exhibit a shoulder extending below the Fermi level; i.e., there are filled $p$ states in the adsorbed $\mathrm{Hg}$ atom. As mentioned above, the charge density difference showed evidence for charge transfer into the LUMO of $\mathrm{Hg}$ on the $\mathrm{Au}$ and $\mathrm{Ag}$ surfaces. Integration of the filled $p$ states in the adsorbed $\mathrm{Hg}$ atom indicates that the amount of charge transferred to the $\mathrm{Hg}$ atom via this trans- formation is small and similar across the four metals examined here. However, the Wigner-Seitz radius for $\mathrm{Hg}$ used for the decomposition of the density of states $(1.614 \AA)$ is unfortunately too small to extend into the area where charge donation from the metal to $\mathrm{Ag}$ and $\mathrm{Au}$ was observed in the charge density difference shown in Fig. 5.

The $d$ bands for bare Ag and Au do not have states at the Fermi level, while Pd and Pt have a large Fermi-level surface density of states. The $d$-band centers for the bare $\mathrm{Ag}, \mathrm{Au}, \mathrm{Pd}$, and $\mathrm{Pt}$ surface atoms are located at $-3.96,-3.27,-1.82$, and $-2.43 \mathrm{eV}$, respectively, before adsorption of $\mathrm{Hg}$. There is a rough correlation between the level of the $d$ band center for the bare metal surface atoms and the binding energy of $\mathrm{Hg}$ to the surface (presented in Fig. 10) with the metals for which the $d$ band is lower exhibiting weaker binding for $\mathrm{Hg}$. The $d$ bands are slightly lowered in all four cases, to $-4.10,-3.42$, -1.89 , and $-2.50 \mathrm{eV}$, respectively. The $d$-band shift is more pronounced for $\mathrm{Ag}$ and $\mathrm{Au} . \mathrm{Hg}$ adsorption induces a reso- 


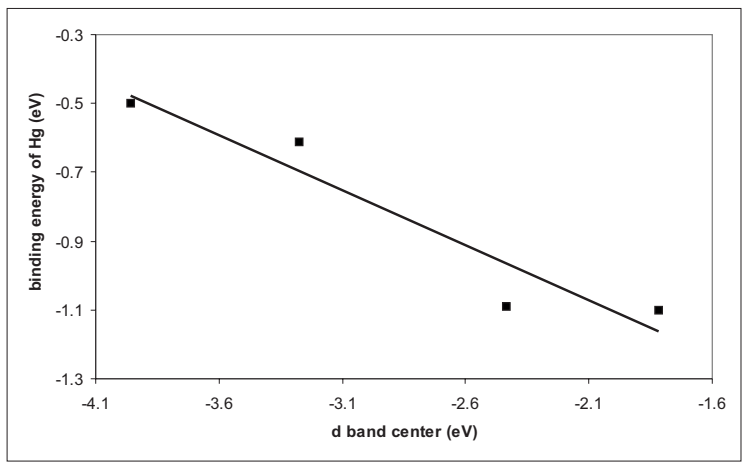

FIG. 10. $E_{a d s}$ for the $c(4 \times 4)-\mathrm{Hg} / M(001)$ overlayer, $M=\mathrm{Ag}$, $\mathrm{Au}, \mathrm{Pd}$, and Pt plotted versus the $d$-band center for the bare surface metal atoms.

nance observable near $-6.5 \mathrm{eV}$, the energy of the $d$ band for adsorbed $\mathrm{Hg}$, in the $s$ states for all four metals and indeed smaller resonances can also be observed in the $p$ and $d$ states as well.

\section{CONCLUSIONS}

In this project, plane-wave DFT calculations are used to characterize the interaction of mercury with copper, nickel, palladium, platinum, silver, and gold surfaces. Mercury binds relatively strongly to the six metal surfaces studied, with binding energies up to $\sim 1 \mathrm{eV}$ for $\mathrm{Pt}$ and $\mathrm{Pd}$. The interaction with mercury in order of increased reactivity over the six metals studied is $\mathrm{Ag}<\mathrm{Au}<\mathrm{Cu}<\mathrm{Ni}<\mathrm{Pt}<\mathrm{Pd}$. With respect to the overlayers for which experimental data are available, it appears that DFT (using the PBE functional) underestimates the energy of adsorption. Binding is predicted to be stronger on the (001) faces of the metal surfaces, where mercury is situated in fourfold hollow sites as opposed to the threefold hollow sites on (111) faces. The current plane-wave DFT calculations using LDA, PW91, and LDA functionals indicate that binding at hollow sites is preferred over other highsymmetry sites, although this result is not consistent with recent relativistic cluster and embedded cluster calculations. ${ }^{27}$ The DFT results are consistent with weak attractive and strong repulsive lateral $\mathrm{Hg}-\mathrm{Hg}$ interactions, which have been posited to interpret experimental results. In general, mercury adsorption leads to decreases in the work function; adsorbate-induced work function changes are particularly dramatic on Pt. A decrease in work function is what would be expected for an electropositive adsorbate based on charge transfer from the mercury to the metal. The direction and magnitude of the calculated change in work function and the Bader charge analysis support a simple Koopmans'theory-based interpretation of charge transfer. On Ag the net charge transfer is small, which may result from a balance between charge transfer from the mercury in to the metal and back-donation from the metal into the LUMO of the adsorbate. This is in contrast to Pt where the binding is based on very pronounced charge transfer from the mercury into the surface, resulting in a dramatic adsorbate-induced decrease in the work function.

\section{ACKNOWLEDGMENTS}

Valuable discussions with Ken Jordan, Karl Johnson, David Sholl, and Dan Sorescu are gratefully acknowledged. This project was performed as part of the NETL in-house research program in Computational Chemistry, which is part of the Research and Development Support (RDS), Contract No. RDS \#DE-AC26-04NT41817. *steckel@ netl.doe.gov

${ }^{1}$ E. B. Swain, P. M. Jakus, G. Rice, F. Lupi, P. A. Maxson, J. M. Pacyna, A. Penn, S. J. Spiegel, and M. M. Veiga, Ambio 36, 45 (2007).

${ }^{2}$ R. K. Srivastava, N. Hutson, B. Martin, F. Princiotta, and J. Staudt, Environ. Sci. Technol. 40, 1385 (2006).

${ }^{3}$ J. H. Pavlish, E. A. Sondreal, M. D. Mann, E. S. Olson, K. C. Galbreath, D. L. Laudal, and S. A. Benson, Fuel Process. Technol. 82, 89 (2003)

${ }^{4}$ S. Ghorishi, C. Lee, W. Jozewicz, and J. Kilgroe, Environ. Eng. Sci. 22, 221 (2005).

${ }^{5}$ A. A. Presto and E. J. Granite, Ind. Eng. Chem. Res. 40, 5601 (2006).

${ }^{6}$ Y. Zhao, M. D. Mann, J. H. Pavlish, B. A. F. Mibeck, G. E. Dunham, and E. S. Olson, Environ. Sci. Technol. 40, 1603 (2006).

${ }^{7}$ E. J. Granite, H. W. Pennline, and R. A. Hargis, Ind. Eng. Chem. Res. 39, 1020 (2000).

${ }^{8}$ E. J. Granite, C. R. Myers, W. P. King, D. C. Stanko, and H. W. Pennline, Ind. Eng. Chem. Res. 45, 4844 (2006).

${ }^{9}$ N. Gaston and P. Schwerdtfeger, Phys. Rev. B 74, 024105 (2006).
${ }^{10}$ P. Ballone and G. Galli, Phys. Rev. B 40, 8563 (1989).

${ }^{11}$ W. Y. Kim, T. Nautiyal, S. J. Youn, and K. S. Kim, Phys. Rev. B 71, 113104 (2005).

${ }^{12}$ B. Paulus and K. Rosciszewski, Chem. Phys. Lett. 394, 96 (2004).

${ }^{13}$ D. Andrae, U. Häussermann, M. Dolg, H. Stoll, and H. Preuss, Theor. Chim. Acta 77, 123 (1990).

${ }^{14}$ W. Küchle, M. Dolg, H. Stoll, and H. Preuss, Mol. Phys. 74, 1245 (1991).

${ }^{15}$ U. Häussermann, M. Dolg, H. Stoll, H. Preuss, P. Schwerdtfeger, and R. M. Pitzer, Mol. Phys. 78, 1211 (1993).

${ }^{16}$ P. Schwerdtfeger, J. Li, and P. Pyykkö, Theor. Chim. Acta 87, 313 (1994).

${ }^{17}$ K. A. Peterson, D. Figgen, E. Goll, H. Stoll, and M. Dolg, J. Chem. Phys. 119, 11113 (2005).

${ }^{18}$ D. Figgen, G. Rauhut, M. Dolg, and H. Stoll, Chem. Phys. 311, 227 (2005).

${ }^{19}$ L. J. Munro, J. K. Johnson, and K. D. Jordan, J. Chem. Phys. 114, 5545 (2001).

${ }^{20}$ N. Gaston, P. Schwerdtfeger, T. Saue, and J. Greif, J. Chem. Phys. 124, 044304 (2006).

${ }^{21}$ N. Gaston, B. Paulus, K. Rosciszewski, P. Schwerdtfeger, and H. 
Stoll, Phys. Rev. B 74, 094102 (2006).

${ }^{22}$ N. B. Balabanov and K. A. Peterson, J. Chem. Phys. 120, 6585 (2004).

${ }^{23}$ N. B. Balabanov and K. A. Peterson, J. Chem. Phys. 119, 12271 (2003).

${ }^{24}$ N. B. Balabanov and K. A. Peterson, J. Phys. Chem. A 107, 7465 (2003).

${ }^{25}$ B. C. Shepler and K. A. Peterson, J. Phys. Chem. A 107, 1783 (2003).

${ }^{26}$ P. Ballone and G. Galli, Phys. Rev. B 42, 1112 (1990).

${ }^{27}$ C. Sarpe-Tudoran, B. Fricke, J. Anton, and V. Persina, J. Chem. Phys. 126, 174702 (2007).

${ }^{28}$ R. G. Jones and A. W.-L. Tong, Surf. Sci. 188, 87 (1987).

${ }^{29}$ P. A. Dowben, Y. J. Kime, S. Varma, M. Onellion, and J. L. Erskine, Phys. Rev. B 36, 2519 (1987).

${ }^{30}$ N. P. Prince, N. K. Singh, W. Walter, D. P. Woodruff, and R. G. Jones, J. Phys.: Condens. Matter 1, 21 (1989).

${ }^{31}$ N. K. Singh and R. G. Jones, Surf. Sci. 232, 229 (1990).

${ }^{32}$ Y. J. Kime, J. Zhang, and P. A. Dowben, Surf. Sci. 268, 98 (1992).

${ }^{33}$ N. K. Singh, P. A. D. M. A. Dale, D. Bullett, and R. G. Jones, Surf. Sci. 294, 333 (1993).

${ }^{34}$ P. R. Poulsen, I. Stensgaard, and F. Besenbacher, Surf. Sci. Lett. 310, L589 (1994).

${ }^{35}$ S. Soverna, R. Dressler, C. E. Düllmann, B. Eichler, R. Eichler, H. W. Gäggeler, F. Haenssler, J.-P. Niklaus, D. Piguet, Z. Qin et al., Radiochim. Acta 93, 1 (2005).

${ }^{36}$ P. A. Dowben, Surf. Sci. Rep. 40, 151 (1990).

${ }^{37}$ P. A. Dowben, D. LaGraffe, D. Li, G. Vidali, L. Zhang, L. Dottl, and M. Onellion, Phys. Rev. B 43, 10677 (1991).

${ }^{38}$ G. Kresse and J. Furthmüller, Phys. Rev. B 54, 11169 (1996).

${ }^{39}$ G. Kresse and J. Furthmüller, Comput. Mater. Sci. 6, 15 (1996).

${ }^{40}$ P. E. Blöchl, Phys. Rev. B 50, 17953 (1994).

${ }^{41}$ G. Kresse and D. Joubert, Phys. Rev. B 59, 1758 (1999).
${ }^{42}$ J. P. Perdew and A. Zunger, Phys. Rev. B 23, 5048 (1981).

${ }^{43}$ D. M. Ceperley and B. J. Alder, Phys. Rev. Lett. 45, 566 (1980).

${ }^{44}$ J. P. Perdew, J. A. Chevary, S. H. Vosko, K. A. Jackson, M. R. Pederson, D. J. Singh, and C. Fiolhais, Phys. Rev. B 46, 6671 (1992).

${ }^{45}$ Y. Wang and J. P. Perdew, Phys. Rev. B 44, 13298 (1991).

${ }^{46}$ J. P. Perdew, K. Burke, and M. Ernzerhof, Phys. Rev. Lett. 77, 3865 (1996).

${ }^{47}$ M. Methfessel and A. T. Paxton, Phys. Rev. B 40, 3616 (1989).

${ }^{48}$ See EPAPS Document No. E-PRBMDO-77-079807 for bulk properties, convergence information, and work function results for the bare surfaces. For more information on EPAPS, see http://www.aip.org/pubservs/epaps.html

${ }^{49}$ A. Migani and F. Illas, J. Phys. Chem. B 110, 11894 (2006).

${ }^{50}$ E. R. Davidson, Methods in Computational Molecular Physics (Plenum, New York, 1983).

${ }^{51}$ D. M. Wood and A. Zunger, J. Phys. A 18, 1343 (1985).

${ }^{52}$ P. Pulay, Chem. Phys. Lett. 73, 393 (1980).

${ }^{53}$ J. Neugebauer and M. Scheffler, Phys. Rev. B 46, 16067 (1992).

${ }^{54} \mathrm{G}$. Henkelman, A. Arnaldsson, and H. Jónsson, Comput. Mater. Sci. 36, 254 (2006).

${ }^{55}$ T. C. Leung, C. L. Kao, W. S. Su, Y. J. Feng, and C. T. Chan, Phys. Rev. B 68, 195408 (2003).

${ }^{56}$ M.-L. Bocquet, A. M. Rappe, and H.-L. Dai, Mol. Phys. 103, 883 (2005).

${ }^{57}$ H. J. Monkhorst and J. D. Pack, Phys. Rev. B 13, 5188 (1976).

${ }^{58}$ P. J. Feibelman, B. Hammer, J. K. Nörskov, F. Wagner, M. Scheffler, R. Stumpf, R. Watwe, and J. Dumesic, J. Phys. Chem. B 105, 4018 (2001).

${ }^{59}$ G. Kresse, A. Gil, and P. Sautet, Phys. Rev. B 68, 073401 (2003).

${ }^{60}$ R. C. van Zee, S. C. Blankespoor, and T. S. Zwier, J. Chem. Phys. 88, 4650 (1988).

${ }^{61}$ T. A. Koopmans, Physica (The Hague) 1, 104 (1933).

${ }^{62}$ Kenneth D. Jordan (private communication). 